\title{
NASA Space Launch System Operations Strategy
}

\author{
Joan A. Singer ${ }^{1}$ and Jerry R. Cook $^{2}$ \\ Space Launch System Program Office, NASA Marshall Space Flight Center, AL 35812, U.S.A. \\ and \\ Christopher E. Singer ${ }^{3}$ \\ Engineering Directorate, NASA Marshall Space Flight Center 35812, U.S.A.
}

\begin{abstract}
The National Aeronautics and Space Administration's (NASA) Space Launch System (SLS) Program, managed at the Marshall Space Flight Center (MSFC), is charged with delivering a new capability for human and scientific exploration beyond Earth orbit (BEO). The SLS may also provide backup crew and cargo services to the International Space Station, where astronauts have been training for long-duration voyages to destinations such as asteroids and Mars. For context, the SLS will be larger than the Saturn V, providing 10 percent more thrust at liftoff in its initial 70 metric ton (t) configuration and 20 percent more in its evolved 130-t configuration. The SLS Program knows that affordability is the key to sustainability. This paper will provide an overview of its operations strategy, which includes initiatives to reduce both development and fixed costs by using existing hardware and infrastructure assets to meet a first launch by 2017 within the projected budget. It also has a long-range plan to keep the budget flat using competitively selected advanced technologies that offer appropriate return on investment. To arrive at the launch vehicle concept, the SLS Program conducted internal engineering and business studies that have been externally validated by industry and reviewed by independent assessment panels. A series of design reference missions has informed the SLS operations concept, including launching the Orion Multi-Purpose Crew Vehicle (MPCV) on an autonomous demonstration mission in a lunar flyby scenario in 2017 , and the first flight of a crew on Orion for a lunar flyby in 2021. Additional concepts address the processing of very large payloads, using a series of modular fairings and adapters to flexibly configure the rocket for the mission. This paper will describe how the SLS, Orion, and Ground Systems Development and Operations (GSDO) programs are working together to create streamlined, affordable operations for sustainable exploration for decades to come.
\end{abstract}

\section{Introduction}

$\mathrm{N}$ ASA's Space Launch System will be a unique infrastructure asset for missions of national and international importance, as the Space Age continues to unfold (Fig. 1). This super-heavy-lift human-rated rocket will be the first exploration-class launch vehicle since the Apollo Program's Saturn V Moon rocket in the 1960s and 1970s. The SLS tenets of safety, affordability, and sustainability are guideposts for developing and fielding a system that is ready to fly in 2017, and that is optimized for streamlined, efficient operations, so that the societal, economic, technological, and other benefits it empowers will far surpass the cost of operating the world's most capable launch vehicle.

\footnotetext{
${ }^{1}$ Deputy Program Manager, SLS Program, Mail Stop XP01.

${ }^{2}$ Associate Program Manager, SLS Program, Mail Stop XP01.

${ }^{3}$ Director, Engineering Directorate, Mail Stop ED01.
} 
The SLS will transport astronauts and cargo such as habitation modules and surface rovers, as well as science payloads such as astronomical telescopes and planetary probes, beyond Earth's orbit. It will provide the capability to perform national and international missions that foster the pursuit of mutual objectives, as outlined in the National Space Policy of the United States of America, June 2010; in NASA's 2011 Strategic Plan; and in the Global Exploration Roadmap. ${ }^{1,2,3}$ Potential destinations for human exploration include asteroids, Lagrange Points, the Moon, and Mars.

Delivering a cost-effective capability is imperative to advancing the global space agenda. Future generations are the ultimate beneficiary of the knowledge that space exploration affords and the associated emerging markets upon which it depends. As summarized below, the SLS Program has developed an operations strategy commensurate with its goals of safety, affordability, and sustainability for entirely new missions beyond Earth's orbit that may benefit all Earth's people.

\section{SLS Team, Partners, and Stakeholders}

The SLS Program is managed from the Marshall Space Flight Center, where its partnerships with the Safety and Mission Assurance Office and the Engineering Directorate provide foundational skills and the experience base to develop the next heavy-lift human-rated space transportation system. The SLS team includes design talent from the Constellation Program and operations experts from the Space Shuttle Program, among others. The SLS Chief Engineer directs systems engineering and integration activities and provides technical management for this nationwide effort. Aerospace prime contractors and the industrial supplier/vendor base are key partners on which the success of this major venture depends.

The SLS Program closely collaborates with its partners the Orion Program at the Johnson Space Center (JSC) and with the Ground Systems Development and Operations Program at the Kennedy Space Center (KSC) through technical interchange meetings, cross-program reviews, and other formal and informal avenues. These important lines of communication foster real-time integration and problem solving. SLS also works closely with its parent organization - the Exploration Systems Development division of the Human Exploration and Operations Mission Directorate at NASA Headquarters - to make informed, integrated decisions that optimize design solutions and support safe, affordable, sustainable operations.

Affordability in this context is defined as the ability to develop and operate the SLS within the national means to sustain funding for the Program. With this in mind, SLS stakeholders provide schedule and technical requirements, as well as funding conveyed in public law such as the NASA 2010 Authorization Act and guidance contained in policy documents such as the NASA 2011 Strategic Plan. Providing maximum value for the American taxpayers' investment demands an accountable, disciplined approach to solving the challenges that come with an engineering feat of this magnitude.

The SLS operations strategy addresses managing stakeholder requirements and incentivizing contractors to find and implement actions that lead to fixed and recurring cost reductions. The SLS Concept of Operations ${ }^{4}$ articulates the expectation for a "culture shift," which places emphasis on cost-as-an independent variable and personal responsibility for keeping costs within bounds. It also provides a framework for defining the outcome of work being done today to fly Orion in 2017 and 2021, while positioning the system for streamlined, efficient operations for additional missions that will be added to the manifest as the Agency solidifies its plans in the months ahead.

The summary below includes non-recurring design, development, testing, and evaluation (DDT\&E) affordability tactics and results, as well as fixed and recurring cost-reduction initiatives that will be implemented in the production and operations $(\mathrm{P} \& \mathrm{O})$ phase. Achieving a safe, affordable, and sustainable SLS will be made possible through the ideas, actions, and commitments of the SLS team, partners, and stakeholders. 


\section{SLS Concept of Operations}

The SLS Program's Concept of Operations describes the system's attributes, as well as how it will be built, tested, shipped, processed, and launched. This document is an objective tool to calibrate and validate stakeholder requirements and expectations as the vehicle design is successively refined, manufactured, tested, operated, and retired, according to NASA's life-cycle regulations and requirements (Fig. 2).

The SLS Program successfully completed its Mission Concept Review (MCR) in March 2011. The SLS architecture was announced by the NASA Administrator in September 2011. The System Requirements Review/System Definition Review (SRR/SDR) technical objectives were completed in March 2012, with the programmatic baseline completed in June. The SLS Preliminary Design Review (PDR) is scheduled for Spring 2013. Throughout this process, changes to the vehicle's baseline, including affordability approaches and implementation, will be captured in the Concept of Operations.

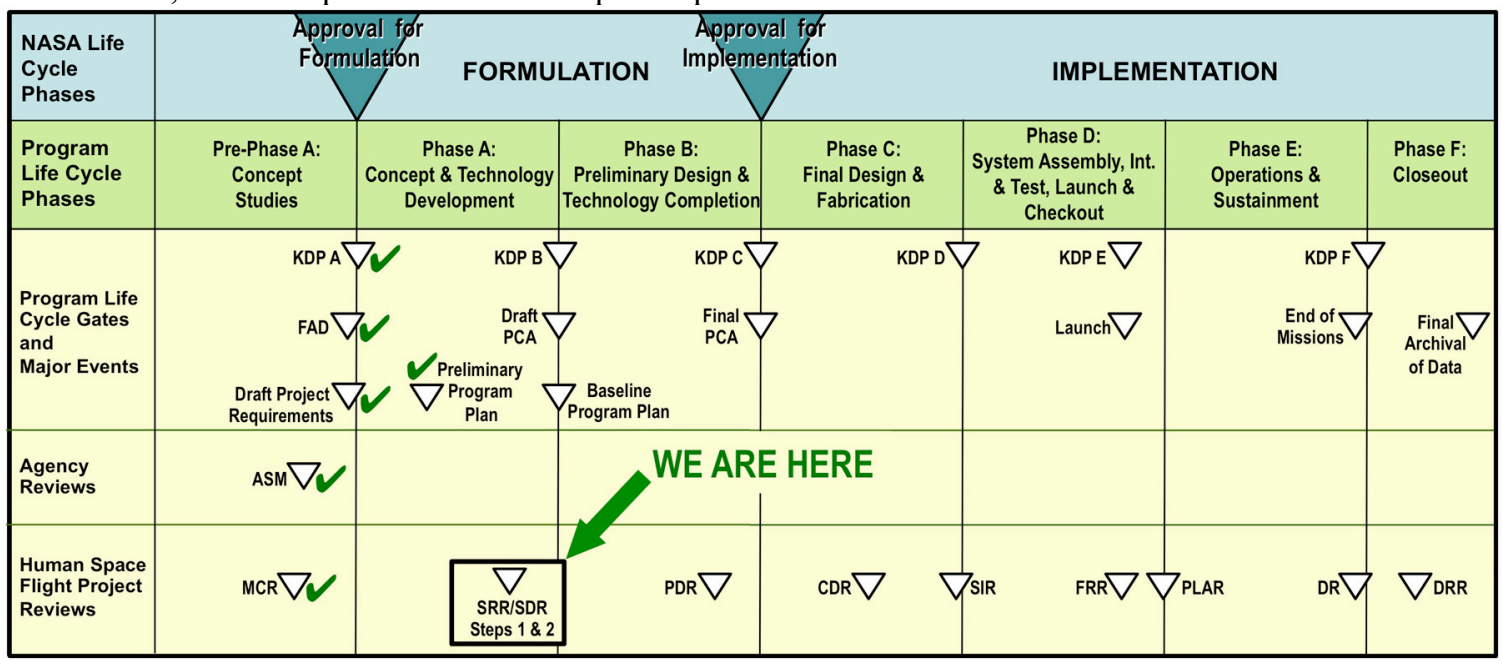

Legend

ASM: Acquisition Strategy Meeting

CDR: Critical Design Review

DR: Decomissioning Review

DRR: Decomissioning Review 2

FAD: Formulation Authorization Document
FRR: Flight Readiness Review KDP: Key Decision Point

PCA: Program Commitment Agreement

PLAR: Post-Launch Assessment Review

SIR: System Integration Review

\section{Figure 2. SLS is in the early design stage.}

Fielding the world's most capable rocket is a commitment of limited resources, so the Agency called on some of the top Government and industry experts to gather the information upon which it based this important architecture decision. Throughout the process, the Agency sought input from internal and external stakeholders, using the affordability figure of merit as a key driver for hundreds of potential architectures that were studied during the selection process.

From the beginning, internal requirements analysis cycle studies and independent analyses performed through a Heavy-Lift Propulsion Technology Broad Agency Announcement identified potential avenues for major cost reductions that are now being implemented. The SLS Program has adopted best practices from industries ranging from automotive to space transportation. These operations and affordability drivers, which are catalogued and referenced in the SLS Concept of Operations, include principles related to leadership focus and direction; cost management techniques and tactics; people costs; supply chain management; and exploring new business models. The Agency has had great success with lean developments and manufacturing, and is applying these approaches to both DDT\&E and P\&O to reduce waste and save money. 


\section{A. SLS Description: Simple, Flexible, Evolvable Design}

Three principles that have been successfully driven into the SLS operations concept and related analyses are: (1) simplicity of design and implementation, (2) evolvable, flexible design to meet specific mission requirements, and (3) margin in performance, cost, and schedule. The current SLS configuration is the most cost-effective choice, while offering unprecedented performance (Fig. 3).

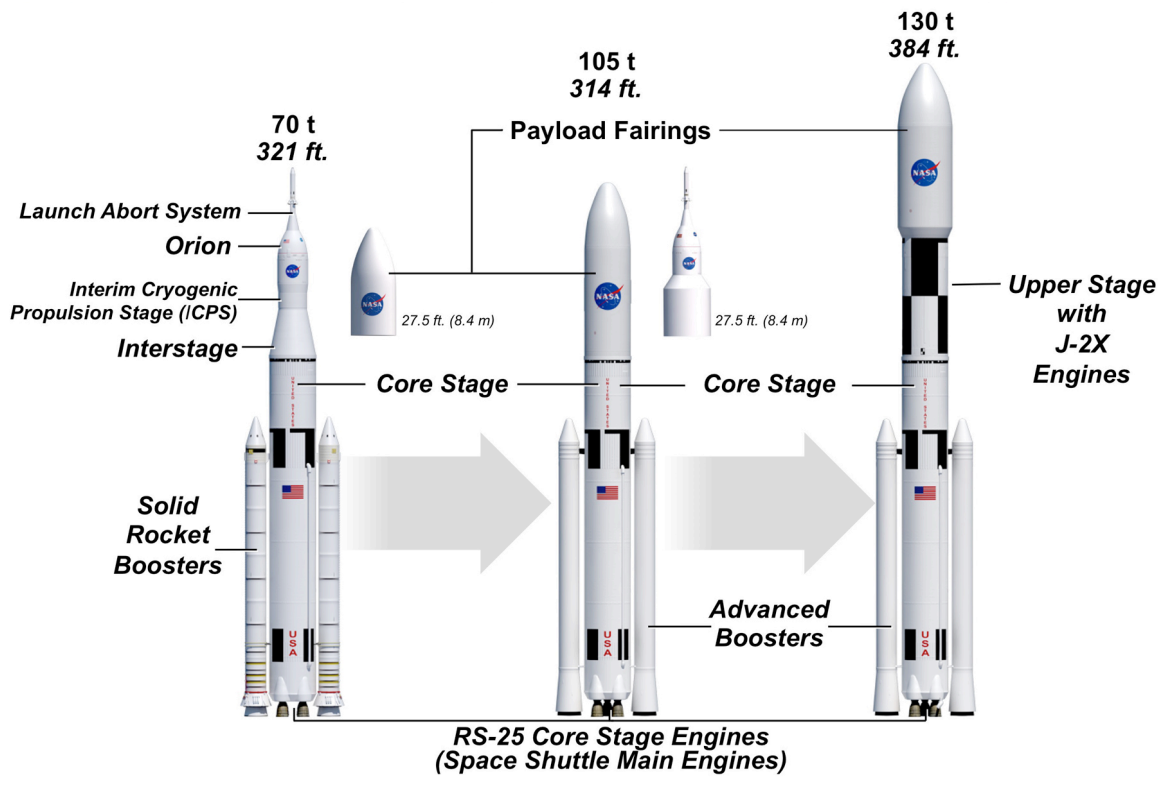

Figure 3. The SLS plan includes a block-upgrade approach to delivering near-term and long-range capabilities.

The NASA Authorization Act of 2010 directs NASA to develop the SLS as a follow-on to the Space Shuttle, with the capability of accessing cis-lunar space and the regions of space beyond low-Earth orbit (LEO) to enable the United States to participate in global efforts to develop this increasingly strategic region. ${ }^{5}$ The Act also provides a series of minimum capabilities that the SLS vehicle must achieve: initially lift 70 metric tons ( $t$ ) to low-Earth orbit and be evolvable to $130 \mathrm{t}$ or more; lift the Orion spacecraft; and serve as a backup system for supplying and supporting cargo and crew delivery requirements for the International Space Station in the event that such requirements are not met by available commercial or partner-supplied vehicles. These requirements drive detailed technical trade studies and resource planning as the SLS concept is refined through the development process, in response to the Agency's specific design reference missions (e.g., high-Earth orbit and geosynchronous-Earth orbit) and figures of merit (e.g., safety, affordability, and reliability).

To reach the goal of first flight in 6 years from authority to proceed, the Agency decided to leverage existing core stage engines in NASA's Space Shuttle inventory and to complete propulsion hardware that is already well into the development phase to keep the DDT\&E budget flat, versus the traditional funding escalation. The SLS offers a relatively simple architecture with competitive opportunities for affordable performance upgrades, as the vehicle is evolved over time.

The basic SLS design comprises a common $27.5-\mathrm{ft}(8.4-\mathrm{m})$ metallic core stage that will contain liquid oxygen/liquid hydrogen (LOX/LH $\mathrm{L}_{2}$ ) tanks to fuel four RS-25 engines (Space Shuttle Main Engines). This takes advantage of 30 years of U.S. experience with $\mathrm{LOX} / \mathrm{LH}_{2}$ propellants, including manufacturing and launching facilities, and uses the 15 flight-ready core stage engines and 2 qualification engines currently in stock, which will support the first several missions (Fig. 4). ${ }^{6}$ These human-rated engines built by Pratt \& Whitney Rocketdyne had a 100-percent mission success rate in support of 135 total Shuttle flights. In a recent decision for how to prepare these valuable assets for flight, the SLS Program descoped the Main Propulsion Test Article and added green-run testing at the Stennis Space Center before mating with the core stage structure and shipping the integrated first stage to the Kennedy Space Center to save almost $\$ 300$ million in development costs. Such decisions are analyzed by engineers 
and business support personnel; recommended by the SLS Chief Engineer, along with supporting cost, schedule, budget, and risk rationale; and approved by the SLS Program Manager.

The core stage also will form the SLS structural backbone. The upper stage for the SLS evolved capability will share common attributes with the core stage, such as its outer diameter, material composition, subsystem components, and tooling, to capitalize on synergies in those areas and positively affect the balance sheet as the vehicle is evolved. The same is true with payload adapter hardware. Various fairings will provide a modular, flexible platform for launching a variety of high-priority missions.

The SLS initial capability will use the world's most powerful solid rocket boosters (SRBs), now in development.

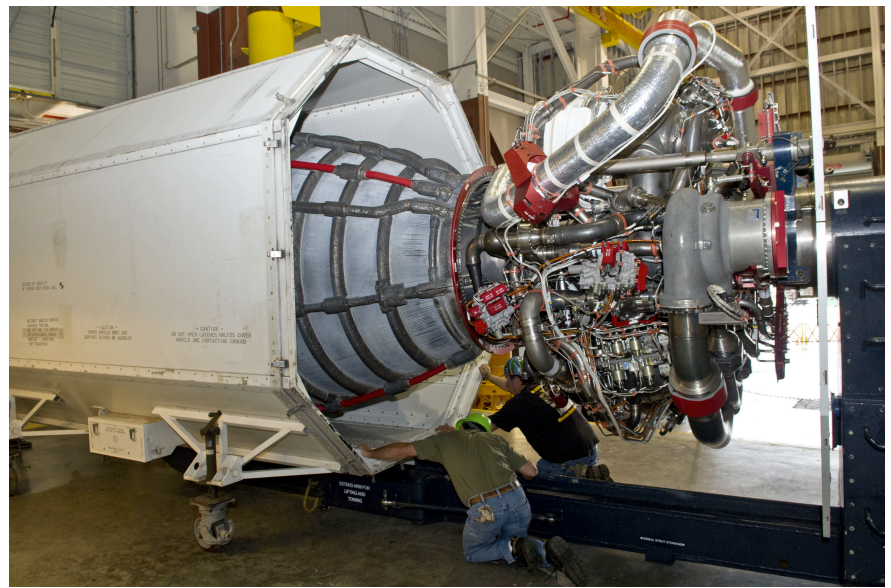

Figure 4. SLS RS-25 core stage engine being transported for storage and green-run testing. The solid rocket motor is designed to generate up to 3.6 million pounds of thrust at launch. Although similar to the Space Shuttle SRBs, the 5-segment SRB includes upgrades such as a larger nozzle throat and upgraded insulation and liner. ${ }^{7}$ To date, the upgraded motor has completed ground testing in the development phase and has begun the qualification phase, with testing scheduled for 2013 (Fig. 5). Prime contractor ATK has conducted extensive lean value-stream mapping (VSM) to streamline the SRB process flow and yield significant savings. Hundreds of changes were identified by the contractor that are projected to improve SRB processing times by nearly 50 percent and reduce project costs by millions of dollars. VSM has been applied to the SRB in all major production areas, including metal refurbishment, insulation, propellant, nozzle, and final assembly. These process improvements received final approval from the SLS Boosters Office in March, and they will be implemented during the fabrication and assembly of the first qualification motor. Later this year, ATK plans to propose VSM improvements for booster separation motor and test area processing.

The SLS evolved capability will require even more advanced boosters that exceed the current limits of today's technology, providing a competitive opportunity for industry to deliver cost-effective, innovative hardware for deep-space missions post-2021. The engineering demonstration and risk-reduction phase for advanced boosters began in late 2011/early 2012, followed by full-and-open competition for DDT\&E. ${ }^{8}$

As the SLS is evolved through planned block upgrades, the J-2X upper stage engine, now in the testing phase, will provide mission flexibility right-sized for performance requirements (Fig. 6). An advanced version of the Saturn's IVB and Saturn V launch vehicle upper stage engines, the $\mathrm{J}-2 \mathrm{X}$ will generate approximately 294,000 pounds of thrust to LEO, or 242,000 pounds of thrust from LEO into deep space, again using $\mathrm{LOX} / \mathrm{LH}_{2} .{ }^{9}$ The $\mathrm{J}-2 \mathrm{X}$ is designed to start and restart while on orbit, unlike the RS-25, which is designed to start while on the ground.

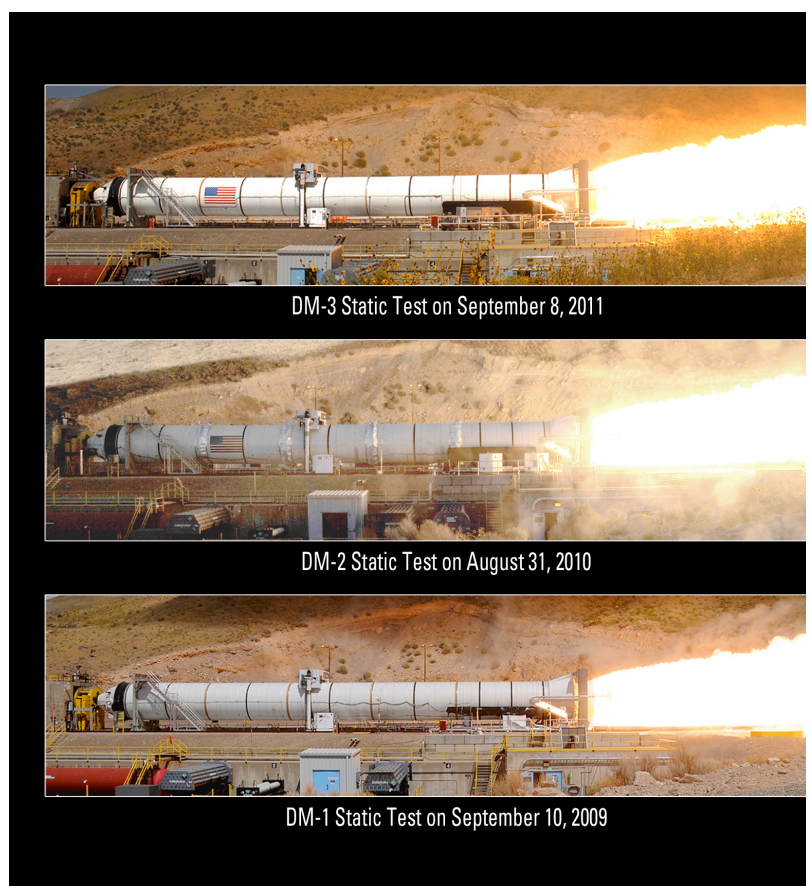

Figure 5. Solid rocket booster development test series. 
While the SLS operations concept defines surge capacity and a robust system that can sit on the launch pad in a state of readiness for months at a time, the SLS architecture is being developed around a low rate of missions (nominally, one per year), so any additional missions will make it even more affordable.

NASA is employing modern manufacturing and vehicle processing techniques, implementing risk-based insight/oversight practices, and streamlining contractor deliverables. For example, applying a lesson from the Constellation Program, SLS has streamlined its decision-making process, including reducing the number of working groups and formal boards, and clarifying lines of authority and each team member's roles and responsibilities. As another example, the amount of formal deliverables required of contractors has been reduced by as much as 80 percent. There are no Type 1 documents that must be approved by

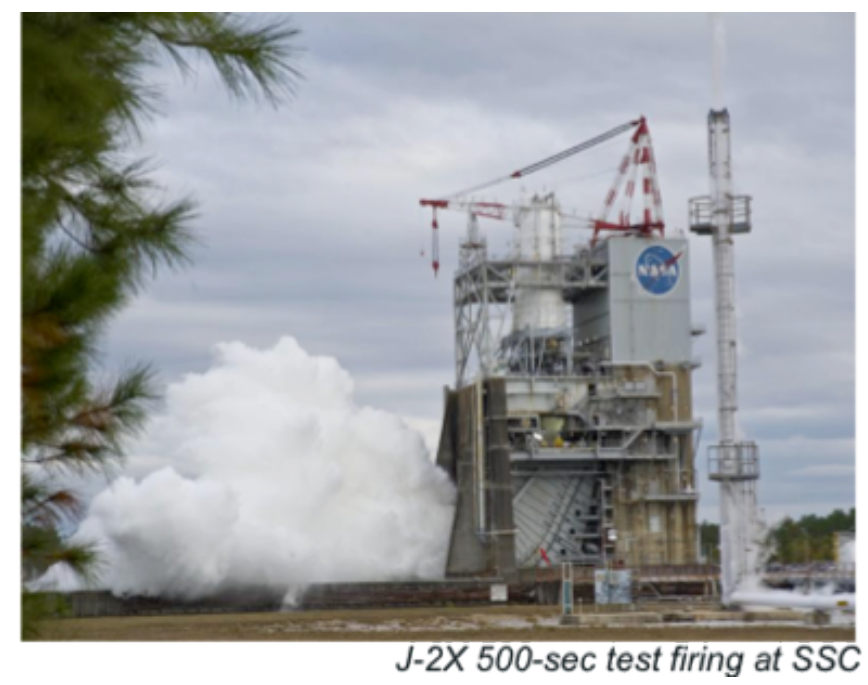

Figure 6. The SLS J-2X upper stage engine is in the testing phase. the Government (versus hundreds in the Constellation Program), and deliverables are accepted electronically in the contractor's preferred format to save money on production and reproduction costs. Documentation reviews focus on how requirements are addressed, versus editorial comments. Cumulatively, simple improvements such as these add up to significant savings.

In the area of robust margins, the SLS Program holds reserves to be able to trade performance for cost and schedule. As one example, the decision to use Aluminum (Al) 2219 instead of Aluminum-Lithium (Al-Li) 2195 for the core stage was based on a trade study that reduced payload mass by $3 \mathrm{t}$, but that will result in approximately $\$ 30$ million per flight savings. From a programmatic perspective, each hardware element office holds management reserves, allowing decisions to be made at a subsystem level and approved at the system level. SLS employees and partners will be continually challenged to strike a balance between having performance margin to spare and keeping adequate budget reserves to address the unexpected challenges that arise during an endeavor of this magnitude.

\section{B. Planned and Potential Missions}

The SLS changes the paradigm of what can be launched because its performance and fairing size will far exceed than that of any current or planned vehicle. In addition to launching the Orion spacecraft, the SLS will provide a super-heavy-lift capacity, allowing satellites and spacecraft to be launched with much higher masses. Dramatically larger fairings will be attractive for multi-element systems, science instruments with greater mass fraction, larger electrical power supplies, and more physical mass for radiation shielding. This translates into positive return on investment for the SLS user community through reduced mission times and the ability to design more straightforward, less complex payloads.

To give context for the operations flow that follows, the first two SLS missions will send Orion all the way to the Moon (Fig. 7). Exploration Mission One (EM-1), scheduled for 2017, will send an uncrewed Orion MPCV on a high-angle lunar trajectory to test the spacecraft's systems - especially the heat shield and reentry parachutes - as well as the SLS rocket. EM-2, scheduled to fly in 2021, will send a crew into orbit around the Moon and back for the first time since 1972. The Orion spacecraft will provide emergency abort during the launch ascent phase, sustain the crew during space travel, and provide safe reentry from deep space return velocities. ${ }^{10}$ 
EM-1

- Un-crewed circumlunar flight - free return

trajectory

- Mission duration $\sim 7$ days

- Demonstrate integrated spacecraft systems

performance prior to crewed flight

Demonstrate high speed entry $(\sim 11 \mathrm{~km} / \mathrm{s})$ and

Thermal Protection System prior to crewed fligh

- SLS Block 1: two 5-segment SRBs, four RS-25

core stage engines

- Interim Cryogenic Propulsion Stage (ICPS)

- Launch from Kennedy Space Center (KSC)

Launch Complex (LC) 39B
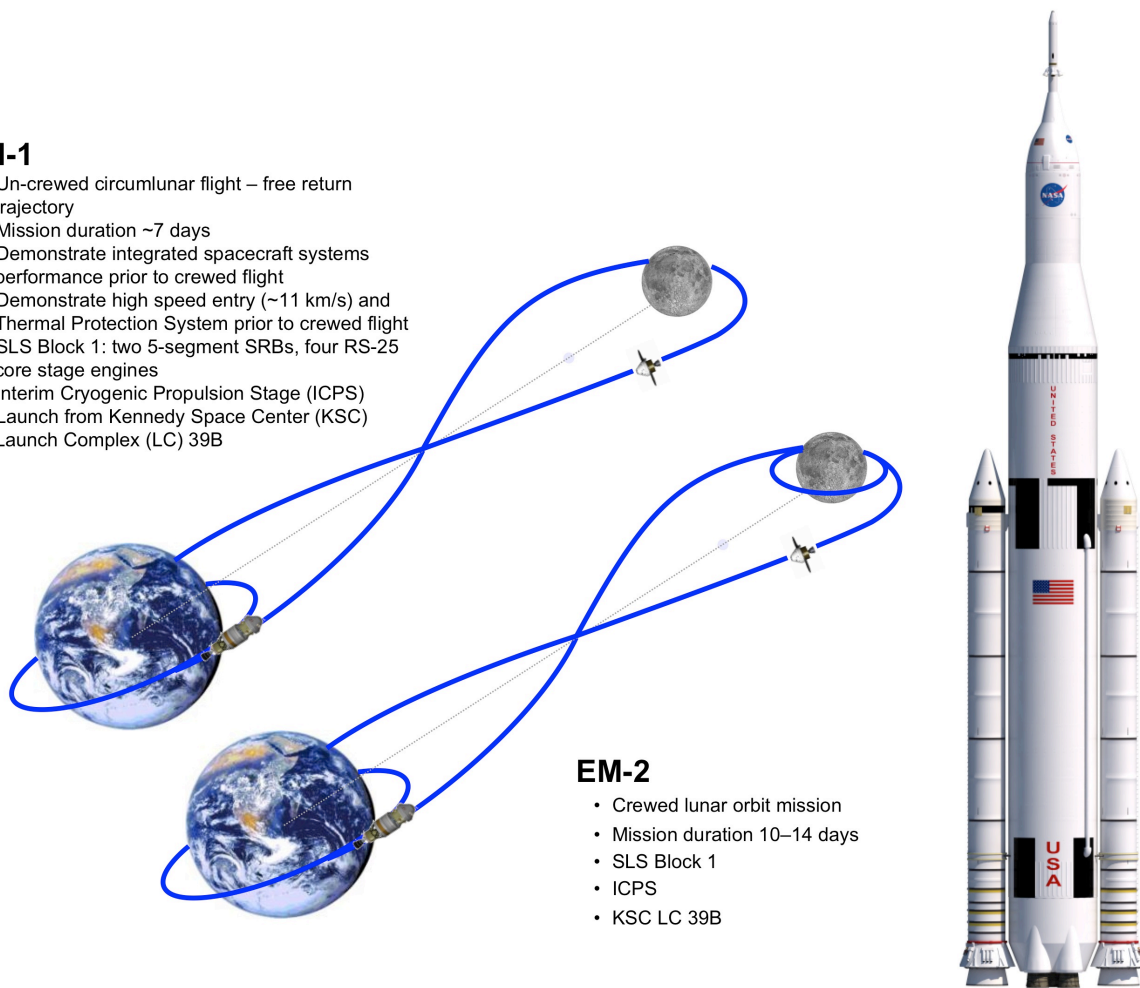

Figure 7. EM-1 and EM-2 are the first flights of the SLS/Orion.

The SLS will be designed to support a surge to a maximum of three launches in a 12-month period to support NASA's capability-driven framework, which scopes one to three launches per mission campaign. The SLS will be interchangeable within a block configuration with any payload type (Orion, cargo, Orion plus cargo) such that no significant changes in processing flow will be required.

In addition, SLS elements and line replaceable units (LRUs) below the payload adapter (refer to Fig. 3) will be interchangeable at the launch processing facility at KSC. The payload adapter will provide a common interface to the vehicle's core stage or upper stage, while supporting various configurations of Orion and other payloads. The launch infrastructure is being built such that it provides a common frame, with the option of adding access platforms and moving umbilical interfaces up for the Block $1(70 \mathrm{t})$ to the Block 1A (105 t) and the Block $2(130 \mathrm{t})$ transitions (Fig. 8). These and other modular/interchangeable hardware and infrastructure augmentations are keys to reducing costly touch-labor and keeping SLS affordable in the out-years.

\section{Launch Vehicle Processing}

The SLS mission operations function consists of several phases conducted by a cadre with clearly defined roles and responsibilities, including the mission planning phase, the mission training phase, the flight operations phase, and the post-flight activities phase. The SLS Flight Evaluation Task Team will coordinate with the SLS Ground Operations Task Team to ensure that all element- and vehicle-level objectives - from vehicle assembly through ascent and beyond - are addressed. The facilities required to implement the mission operations function include but are not limited to the JSC Mission Control Center, the MSFC Huntsville Operations Support Center operated by the Engineering Directorate, and various KSC Ground Systems Development and Operations facilities.

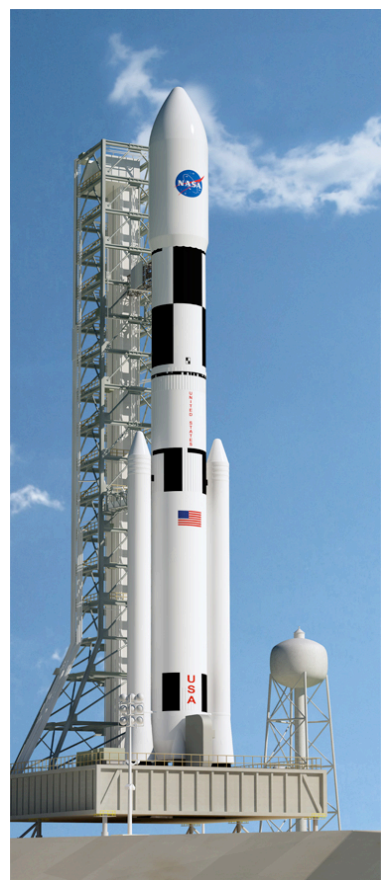

Figure 8. Here, the SLS 130-t vehicle is ready for launch. (artist's concept) 
There are a number of steps involved in readying the launch vehicle for the first two Orion missions, as well as for others that will soon be manifested (Fig. 9). Given below is a top-level synopsis of the steps that will be followed to ready the SLS for its initial missions.

\section{Block 1}

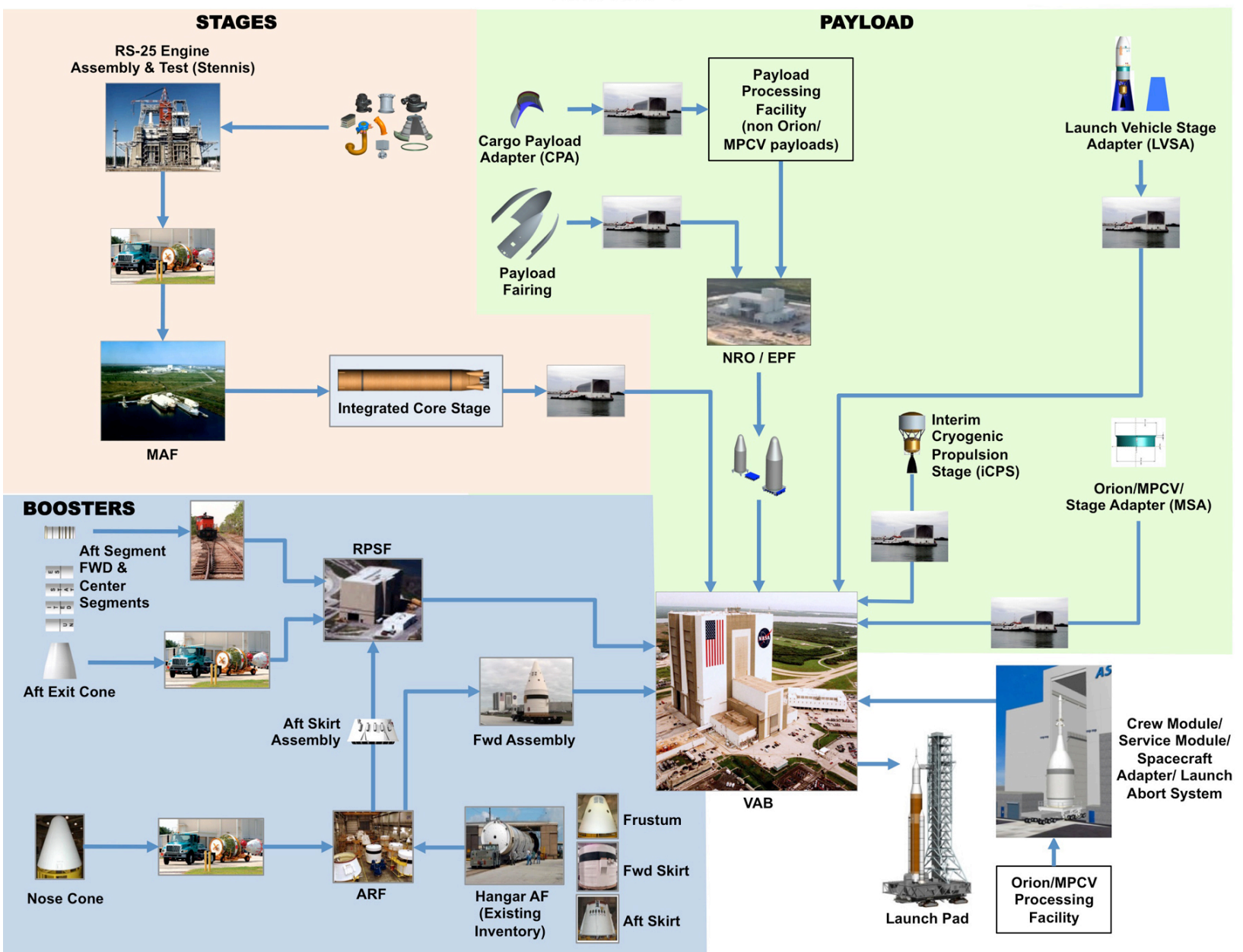

Figure 9. A typical process flow for the SLS Block 1 (70-t) configuration is shown here.

\section{Manufacturing and Logistics}

The SLS elements will be designed and managed so that no planned open manufacturing work will be done at the launch site. Stages will be manufactured by the contractor at NASA's Michoud Assembly Facility (MAF) in New Orleans, Louisiana, where Orion also is being fabricated. The solid rocket boosters will be built at the prime contractor's plant in Promontory, Utah. The core stage engines will be tested at the Stennis Space Center in southern Mississippi, and shipped to MAF for integration. The integrated stage will travel by barge to KSC, while the solid rocket boosters will be transported by rail. Any task that can be done at the contractor's facility-including test and checkout activities - will be completed there to minimize processing costs.

\section{Ground Operations}

At KSC, the Ground Systems Development and Operations Program manages and performs ground operations, which involve assembly, integration, and testing of the vehicle, as well as launch pad operations. A single-string architecture will be used - one high bay in the Vehicle Assembly Building (VAB), one Mobile Launcher (ML), and one launch pad at Launch Complex 39B - to reduce integration complexity. The SLS will be assembled and integrated vertically on the ML in the VAB, then rolled out to the launch pad for final checkout. The SLS will be made ready to launch within a 1-week timeframe to minimize the need for limited-life items and consumable servicing during pad operations. 


\section{Launch}

Countdown operations will be conducted in the KSC Launch Control Complex through first motion of the SLS rocket. Vehicle health and status data will be monitored. Cryogenic propellants will be loaded, and all propellant replenishing and/or pressurization activities completed. Launch holds will be accommodated to minimize battery depletion and the chance of a scrubbed launch. If present, the crew will board the Orion spacecraft via the access arm late in the countdown, in order to limit their waiting time while suited-up for launch.

Final configuration, checkout, and monitoring will be performed remotely. The SLS will switch to internal power. Autonomous handover to the rocket will occur. It will accept ground-computed mission parameters (verified prior to launch) via a ground system hard-line. Remaining final configuration and automated verification of systems will be completed.

Launch control and mission managers will then make a go/no-go decision for launch, based upon their evaluation of compliance with launch commit criteria and flight and range safety rules. Nominal terminal countdown will result in launch at Time Zero (T-0) when the SLS rocket's flight computer will receive the signal to start main engines and fire boosters, the vehicle will be released from hold-downs, the T-0 umbilicals will disconnect, and the integrated stack will lift off from the launch pad.

\section{Ascent and Disposal}

Ascent begins at first motion as the SLS rocket lifts off the pad and ends with disposal of the core stage. Flight operations include disposal of the other SLS elements, as described below. The SLS rocket provides automated and autonomous flight operations on board during launch and ascent. It manages the states and modes of the SLS integrated vehicle systems, as well as any failures, as the Orion spacecraft and/or payload are transported safely to the ascent target. The SLS rocket provides power to all integrated subsystems and elements; performs guidance, navigation, and control; and provides propulsion to the integrated stack. It monitors vehicle health and status and controls the integrated vehicle trajectory, as well as provides attitude control of the stack during ascent. Alternately, remote sources (e.g., the Orion spacecraft) can issue the command to terminate thrust after booster separation, if needed.

Experience has shown that expendable hardware is less costly to design, build, and operate than reusable systems. Disposal begins when the SLS boosters separate, sinking in the Atlantic Ocean after impact, which saves money on recovery and refurbishment. The SLS core stage will continue to burn until orbit is achieved and cutoff is internally commanded. During cargo missions, the SLS payload fairing will be jettisoned, sinking in the Atlantic Ocean after impact. During crewed missions, the Orion spacecraft's service module fairing will be jettisoned in a similar manner. The SLS core stage will separate after the Orion spacecraft and/or payload is inserted into the ascent target. It will follow a trajectory designed to ensure safe disposal in an uninhabited area of the ocean, where it will break up and sink upon impact.

\section{Sustaining Engineering}

Sustaining engineering operations will include post-flight analysis and performance assessment for each SLS flight. Data services provided will include recording, archiving, and retrieving data, which will be used to identify improvements in design, manufacturing processes, and ground processes for future flights. This analysis will include performance trends, failure causes and effects, root cause analysis, imagery analysis, reliability and maintainability trends, and safety hazards. Safety issues will be addressed immediately in the production flow and take priority. Other issues will be forwarded to block-upgrade planning.

Sustaining engineering operations will be focused on vehicle production and engineering services, block upgrades, infrastructure maintenance, launch operations, and post-flight analysis. The block upgrade approach will be periodically applied to address design changes to improve operability, understand previous flight anomalies and marginal performance trends, improve manufacturing affordability, cover obsolescence issues, and so forth. Engineering services also will focus on maintaining the vehicle's production schedule in support of the SLS manifest. These services will address supply chain management, manufacturing and transportation infrastructure maintenance, and anomaly resolutions.

\section{E. SLS Benefits from Orion's 2014 Test Flight}

As a final operations strategy example, the SLS and Orion Programs have signed a bilateral exchange agreement that allows the MPCV Stage Adapter (MSA) interface to be used during Orion's upcoming Exploration Flight Test (EFT-1) in 2014 (Fig. 10). It will be part of the stack when the Orion test article is launched on a Delta IV rocket during the EFT-1 Earth-orbit mission, as well as on the SLS rocket during its beyond Earth orbit missions. 
The MSA is being designed once for both applications, as part of NASA's aggressive pursuit of affordable solutions for the human exploration of space. This is an example of commonality of hardware that supports flexibility, while reducing costs by minimizing the number of unique hardware items that must be developed and processed for flight. SLS and its partner programs also will use this opportunity to meet several objectives related to ground processing and mission

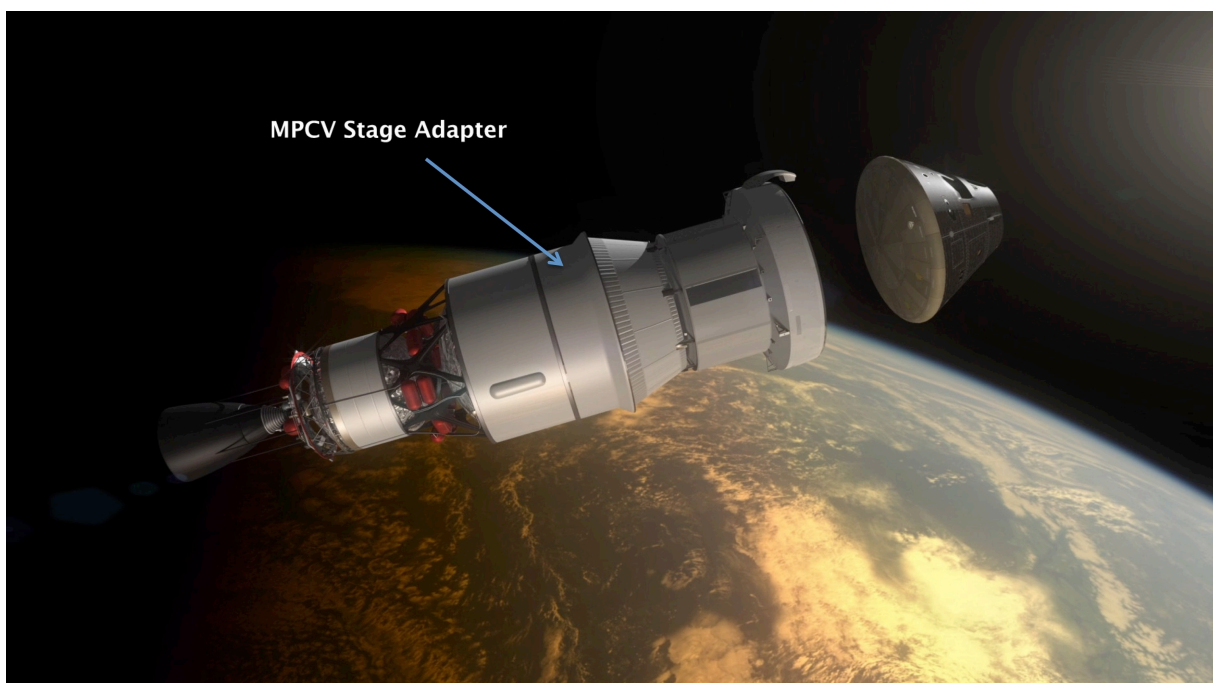

Figure 10. Orion's first flight test will include the SLS stage adapter. (artist's concept) operations.

\section{Conclusion}

NASA's vision is "To reach for new heights and reveal the unknown, so that what we do and learn will benefit all humankind". The first plank in NASA's strategic goals is to "Extend and sustain human activities across the solar system." The SLS (Fig. 11) is integral to establishing a capability-driven framework that will open a frontier filled with possibilities by building on the Apollo, Space Shuttle, and International Space Station experience, and moving out into the solar system.

Creating a sound technical and programmatic climate for sustainable exploration has far-reaching ramifications. Guided by NASA's 2011 Strategic Plan and validated by numerous internal and external and stakeholder organizations, the SLS gives missions defined by NASA, the International Space Exploration Coordination Group, the National Research Council, and others a mode of transportation out of Earth's orbit for astronauts to explore new worlds and for science instruments to rewrite textbooks with new knowledge. The SLS will provide the capacity required for entirely new flagship missions and will be an impressive asset with which to advance the global exploration agenda.

The SLS planning strategy uses existing hardware and finishes developments in progress, as well as incorporates advanced technologies if the return on investment supports affordability goals. The overall development strategy provides incremental stakeholder value by fielding an initial capability that will be successively refined in line with budget realities. Using common elements; simplicity of an evolvable, flexible design; and adequate performance margins and funding reserves support affordability principles that extend from design to operations. The ultimate benefit of the SLS operations strategy will be to decrease the price of flying the Agency's launch vehicle fleet so that more resources can be dedicated to expanding the boundaries of science and technology.

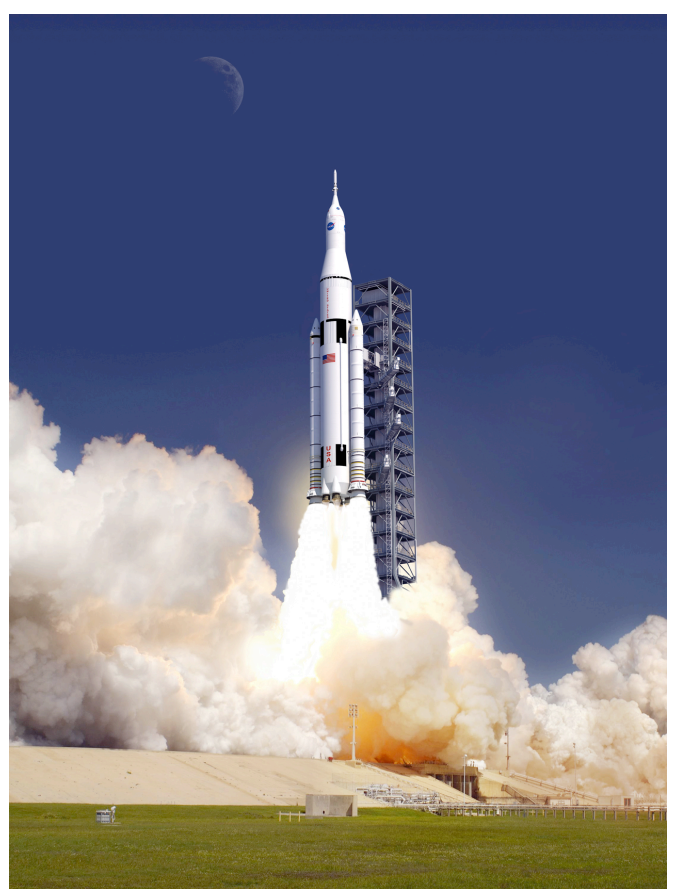

Figure 11. The SLS is slated for first flight in 2017. (artist's concept) See www.nasa.gov/sls for more information. 


\section{References}

${ }^{1}$ The White House, "National Space Policy of the United States of America" [online], URL: http://www.whitehouse.gov/sites/default/files/national_space_policy_6-28-10.pdf [cited 28 June 2010].

${ }^{2}$ National Aeronautics and Space Administration, "2011 NASA Strategic Plan" [online], URL: http://www.nasa.gov/pdf/516579main_NASA2011StrategicPlan.pdf [cited 14 February 2011].

${ }^{3}$ International Space Exploration Coordination Group, “The Global Exploration Roadmap” [online], URL: http://www.nasa.gov/pdf/591067main_GER_2011_small_single.pdf [cited 22 September 2011].

${ }^{4}$ National Aeronautics and Space Administration, "Space Launch System (SLS) Program Concept of Operations (Con Ops) Document," NASA Marshall Space Flight Center, 27 October 2011.

5111th U.S. Congress, "Public Law 267: NASA Authorization Act of 2010" [online], URL: http://www.gpo.gov/fdsys/pkg/PLAW111publ267/html/PLAW-111publ267.htm [cited 11 October 2010].

${ }^{6}$ National Aeronautics and Space Administration, "NASA Moves Shuttle Engines From Kennedy To Stennis" [online], URL: http://www.nasa.gov/home/hqnews/2012/jan/HQ 12-018_Shuttle_Engines_Move.html [cited 12 January 2012].

${ }^{7}$ National Aeronautics and Space Administration, "NASA Successfully Tests Five-Segment Solid Rocket Motor" [online], URL: www.nasa.gov/exploration/features/dm3.html [cited 8 September 2011].

${ }^{8}$ National Aeronautics and Space Administration, "NASA Seeks Space Launch System Advanced Booster Risk Reduction Solutions" [online], URL: http://www.nasa.gov/home/hqnews/2012/feb/HQ 12-051_SLS_Booster_Risk_Reduction_Solutions. html [cited 14 February 2012].

${ }^{9}$ National Aeronautics and Space Administration, "NASA Begins Testing of Next-Generation J-2X Rocket Engine" [online], URL: http://www.nasa.gov/mission_pages/j2x/j2x_ignition.html [cited 14 July 2011].

${ }^{10}$ National Aeronautics and Space Administration, "Explore the Exploration Vehicle" [online], URL: http://www.nasa.gov/exploration/systems/mpcv/explore.html [cited 16 May 2011]. 
NASA's Space Launch System

- Operations Strategy

SpaceOps 2012

Joan (Jody) A. Singer, SLS Deputy Manager Jerry R. Cook, SLS Associate Program Manager Space Launch System (SLS) Program and

Christopher E. Singer, Director Engineering Directorate NASA Marshall Space Flight Center June 2012
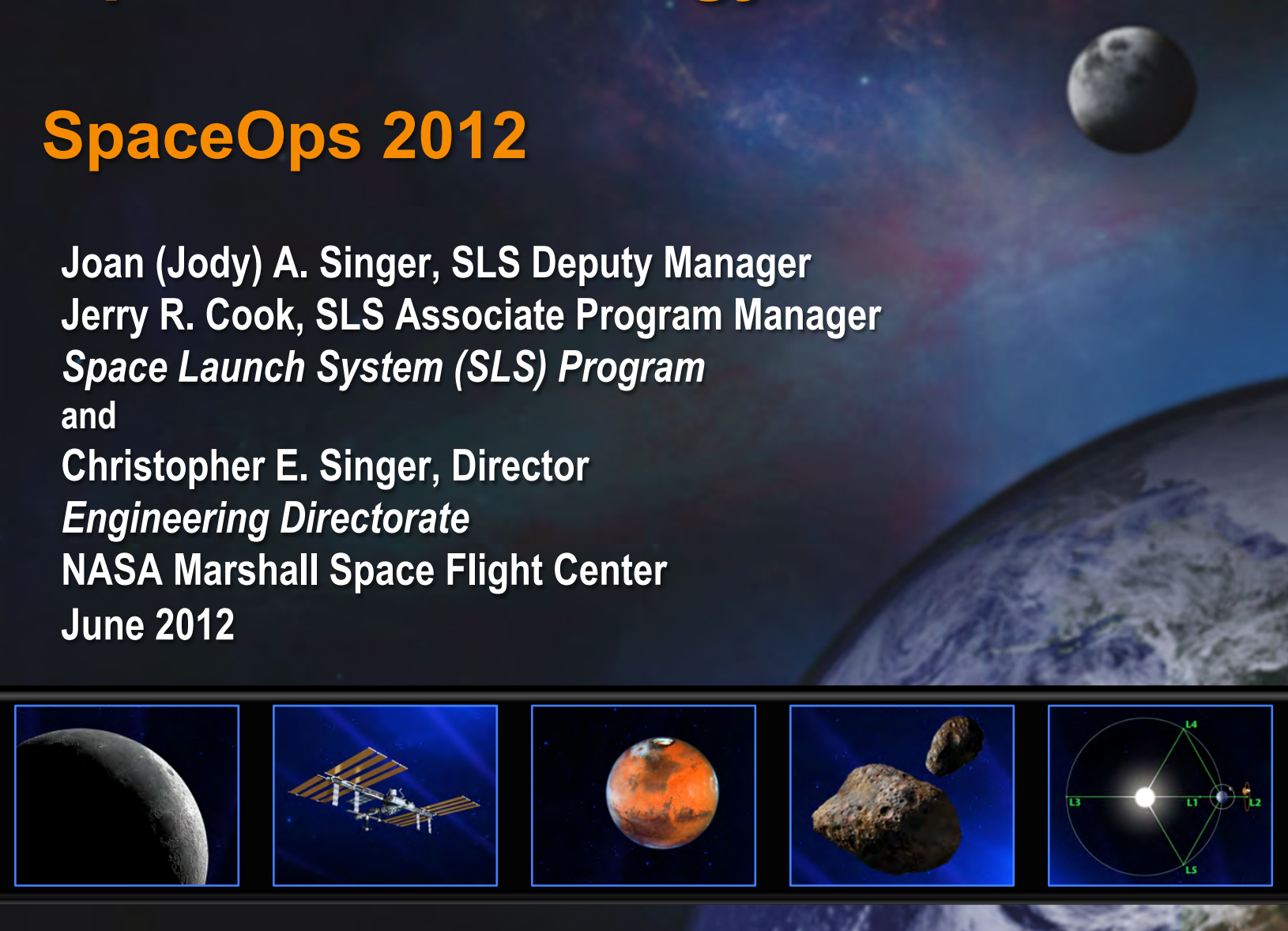
"To reach for new heights... and reveal the unknown so that what we do and learn will benefit all humankind."

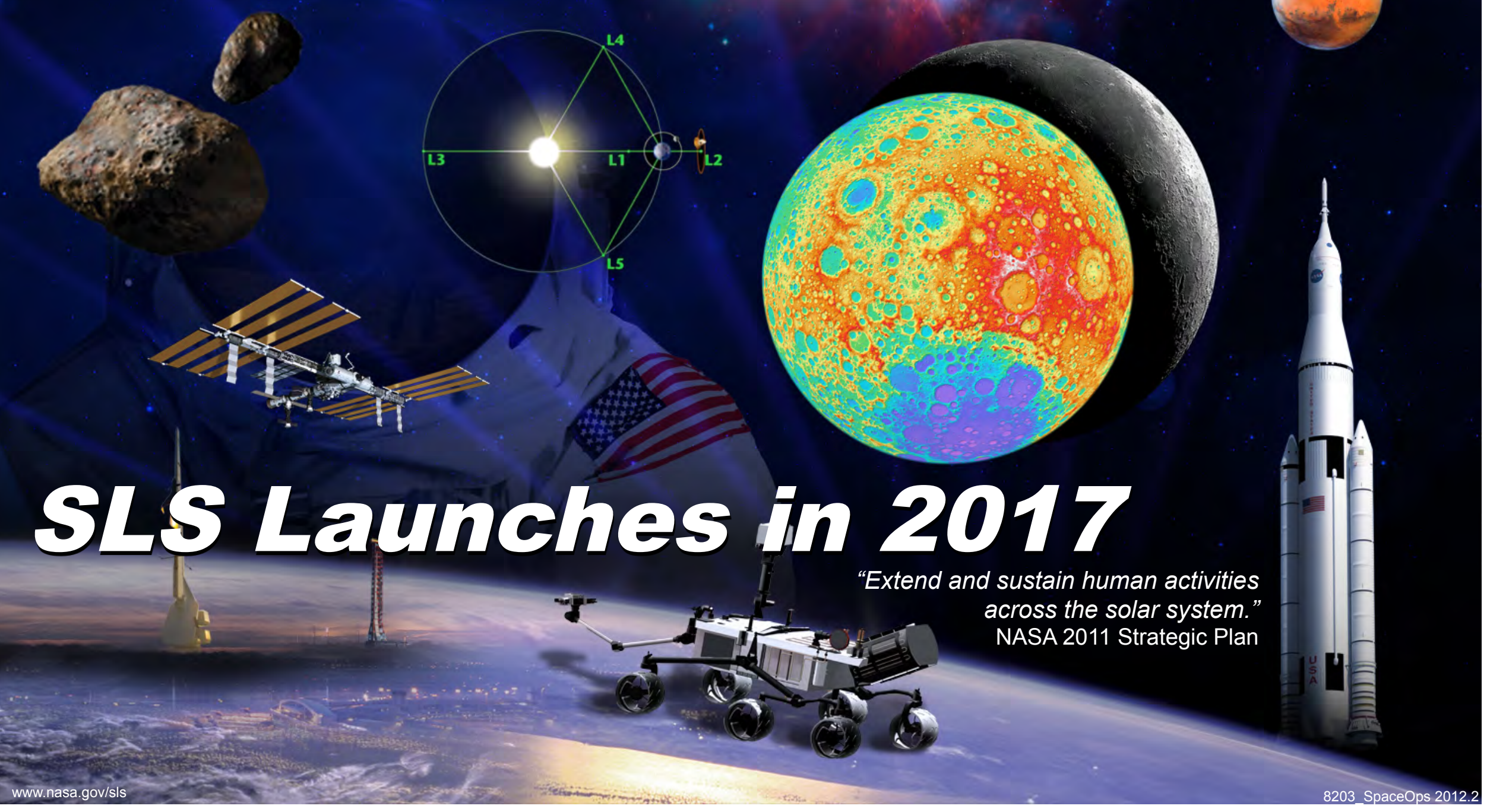




\section{The Future of Exploration}

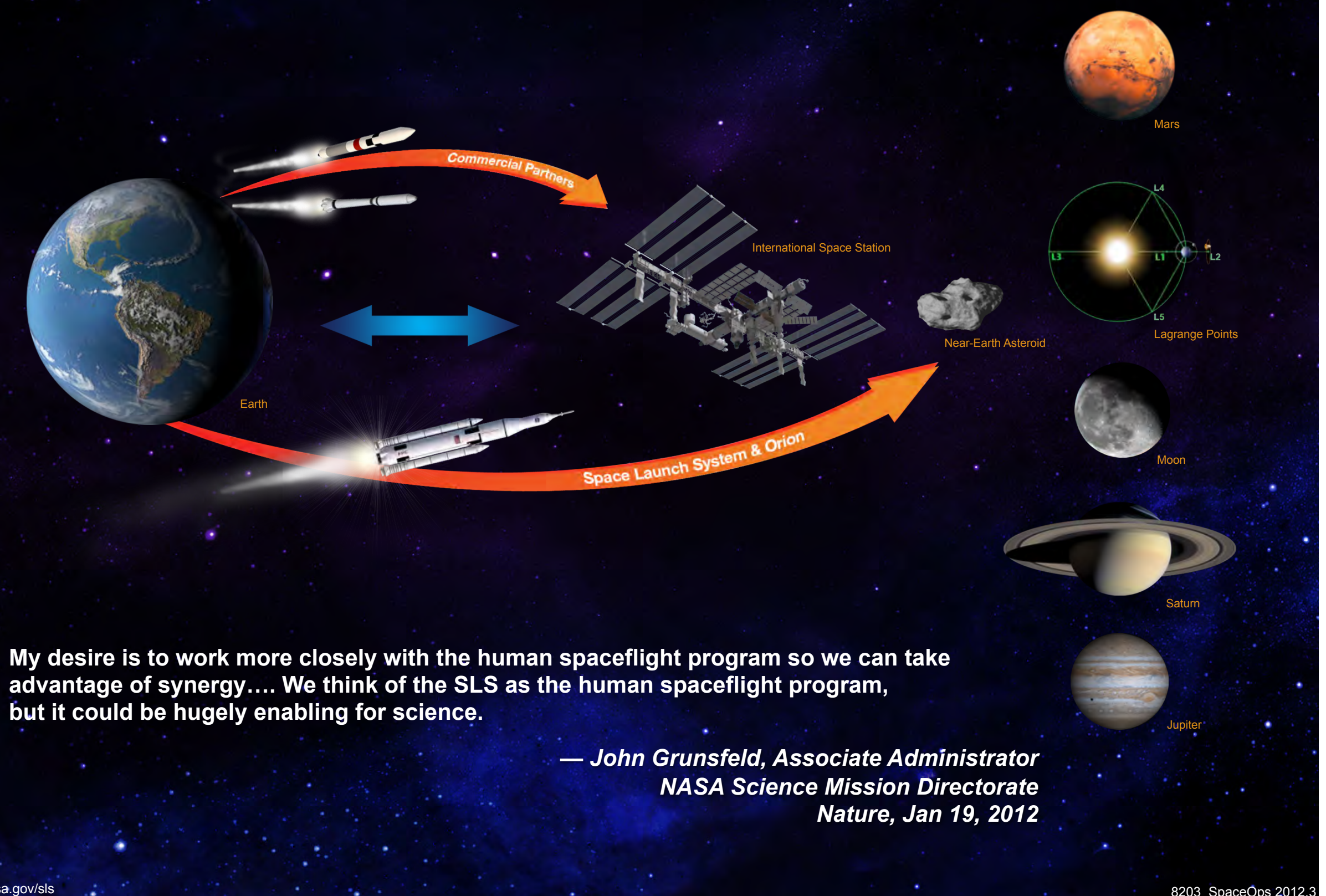




\section{SLS Driving Objectives}

Safe: Human-Rated

$\checkmark$ Affordable

- Constrained budget environment

- Maximum use of common elements and existing assets, infrastructure, and workforce

- Competitive opportunities for affordability on-ramps

\section{Sustainable}

- Initial capability: 70 metric tons (t), 2017-2021

- Serves as primary transportation for Orion and exploration missions

- Provides back-up capability for crew/cargo to ISS

- Evolved capability: $105 \mathrm{t}$ and $130 \mathrm{t}$, post-2021

- Offers large volume for science missions and payloads

- Modular and flexible, right-sized for mission requirements

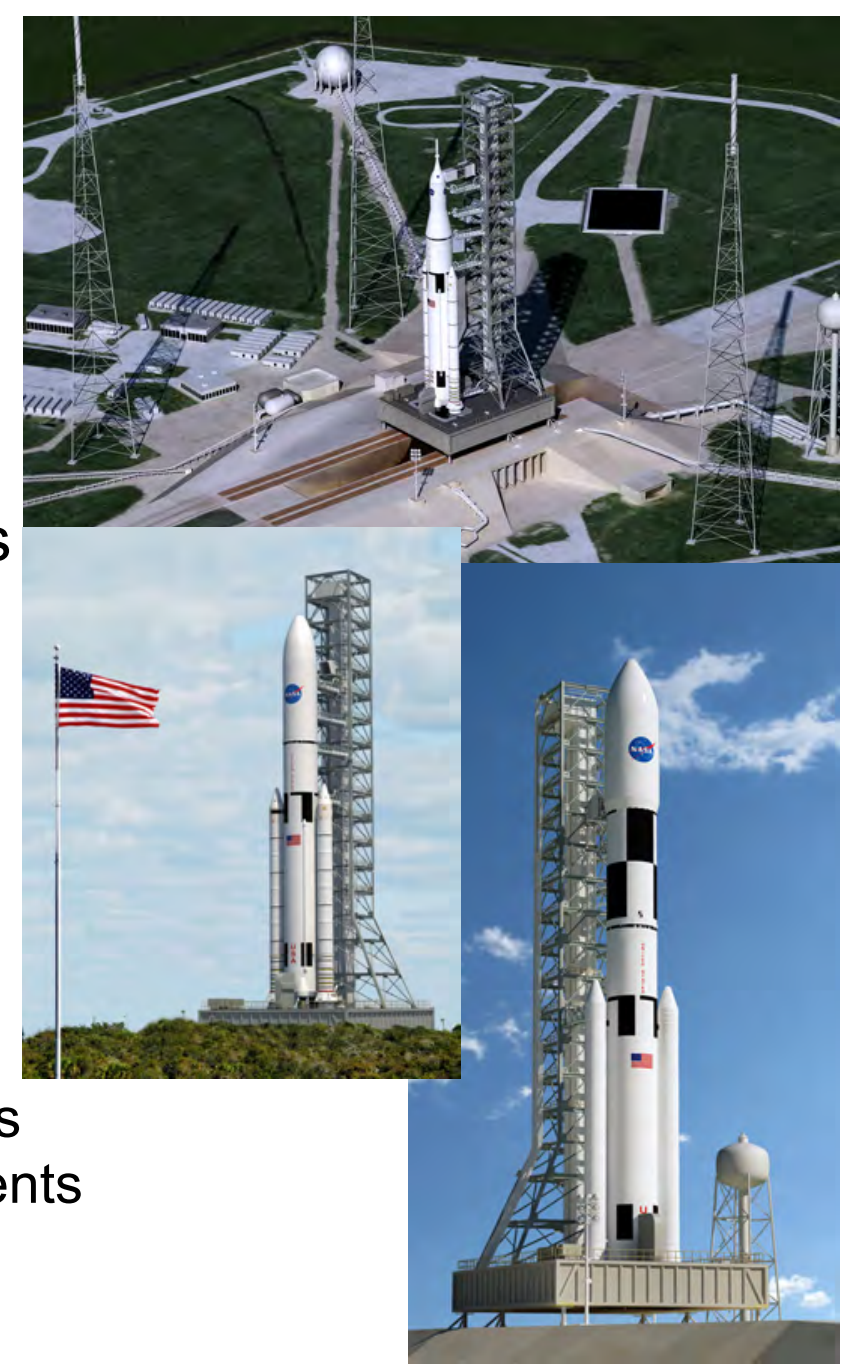

Flexible Architecture Configured for the Mission 


\section{SLS 70 Metric Tons: First Flight 2017}

INITIAL CAPABILITY, 2017-21

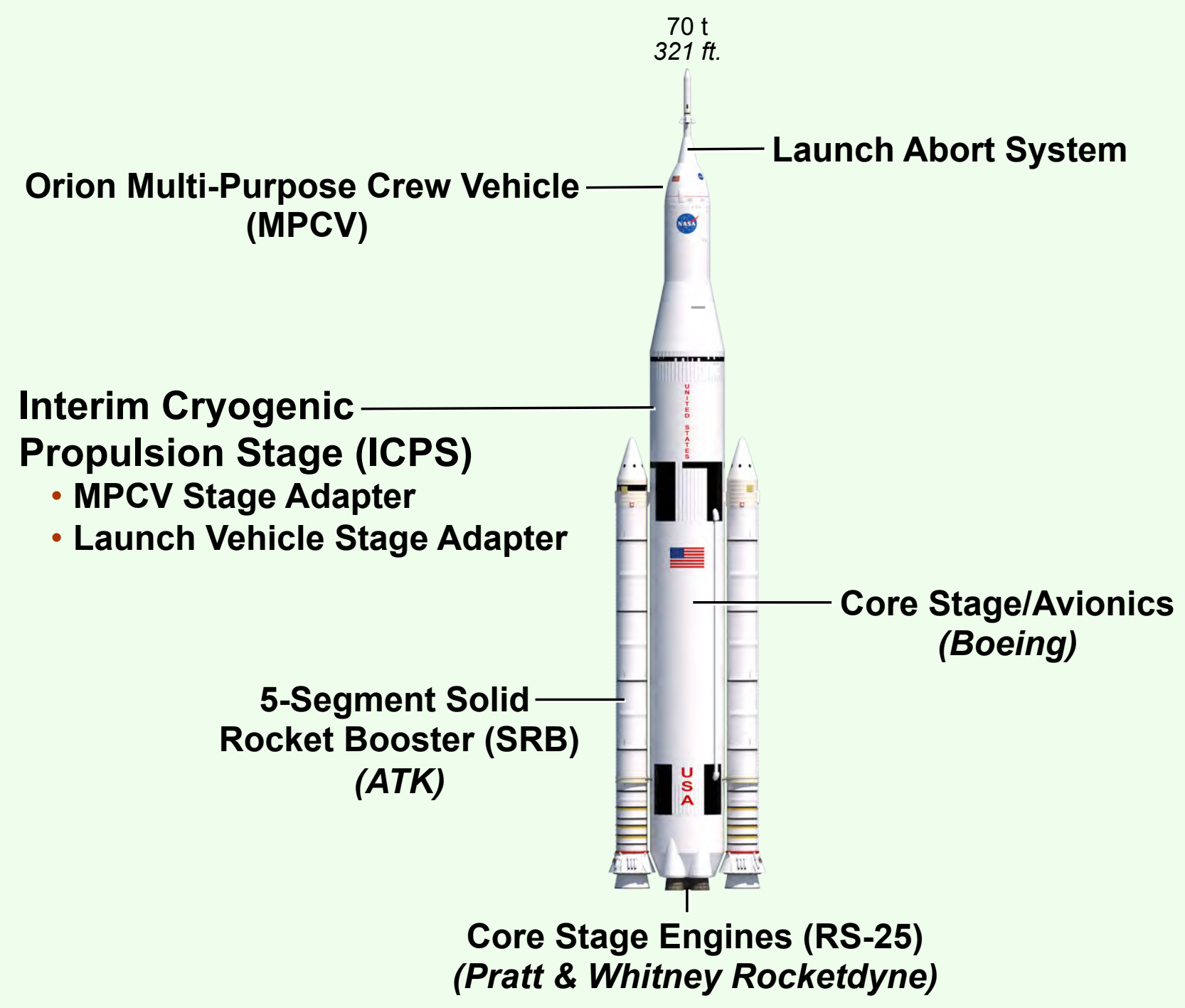

(Pratt \& Whitney Rocketdyne) 


\section{Initial Exploration Missions (EM)}

\section{EM-1 in 2017}

- Un-crewed circumlunar flight - free return trajectory

- Mission duration $\sim 7$ days

- Demonstrate integrated spacecraft systems performance prior to crewed flight

- Demonstrate high speed entry $(\sim 11 \mathrm{~km} / \mathrm{s})$ and

Thermal Protection System prior to crewed flight

SLS Block 1: two 5-segment SRBs, four RS-25 core stage engines

Interim Cryogenic Propulsion Stage (ICPS)

- Launch from Kennedy Space Center (KSC) Launch Complex (LC) 39B

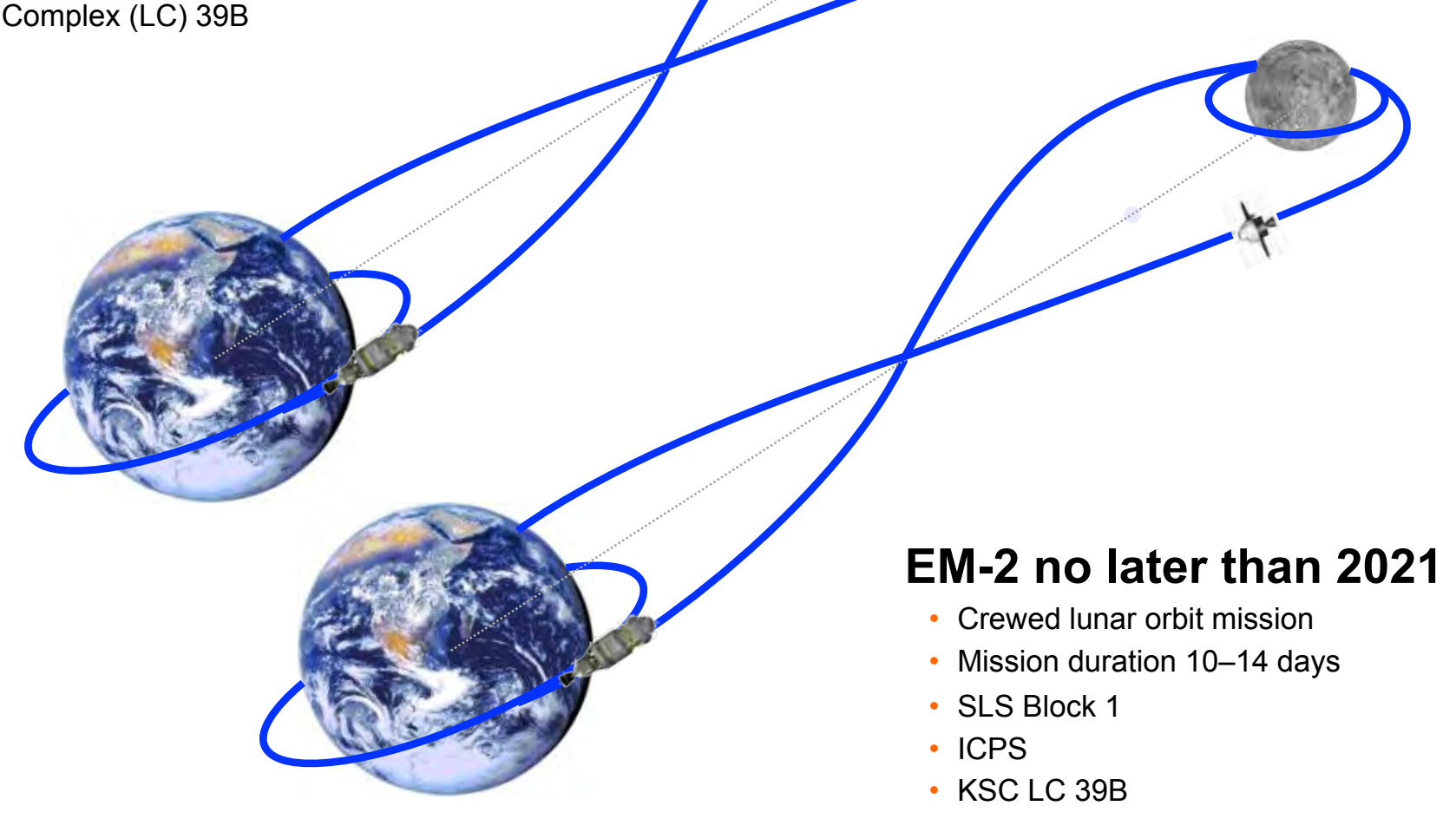

EM-2 no later than 2021

Crewed lunar orbit mission

Mission duration 10-14 days

- ICPS

- KSC LC 39B 


\section{SLS: Being Built Today}

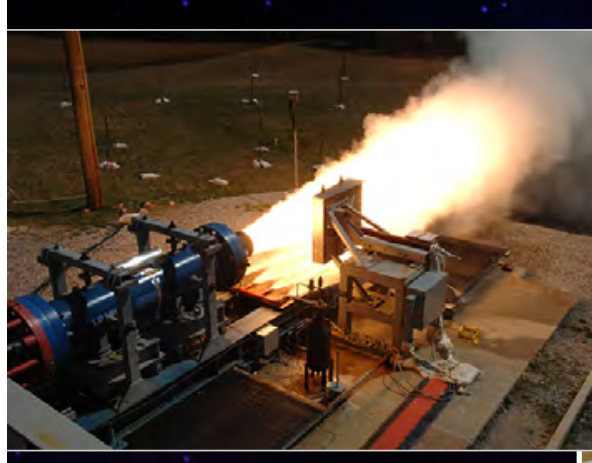

Subscale solid rocket motor test, Marshall Space Flight Center, AL, March 2012.

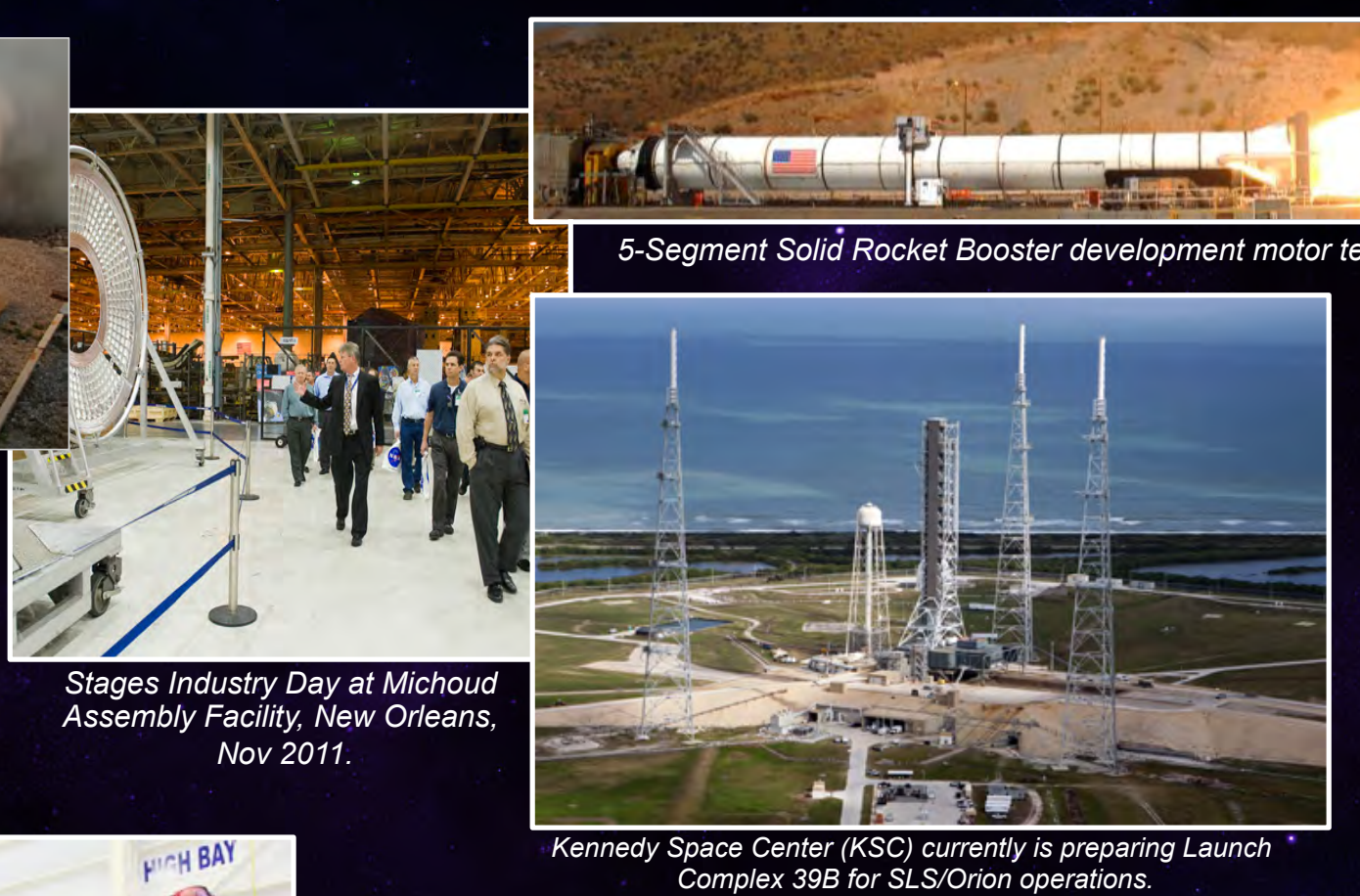

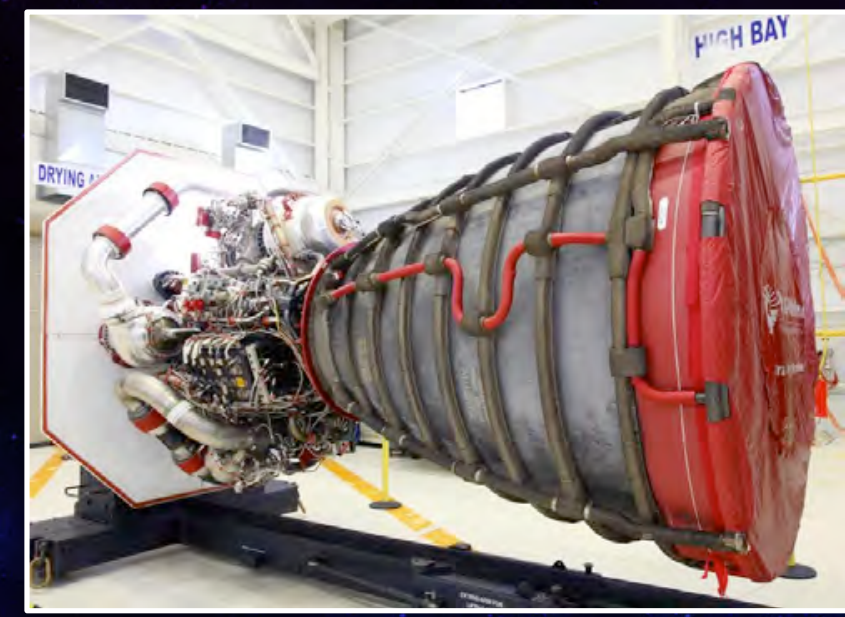

RS-25 Core Stage Engine in the KSC Engine Processing Facility, 2011. *

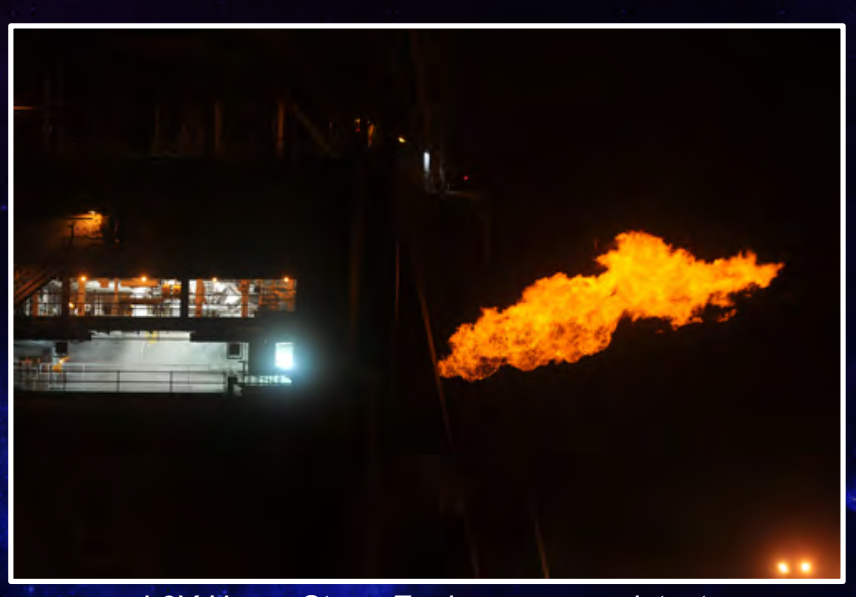

J-2X Upper Stage Engine powerpack test, Stennis Space Center (SSC), MS, Feb 2012

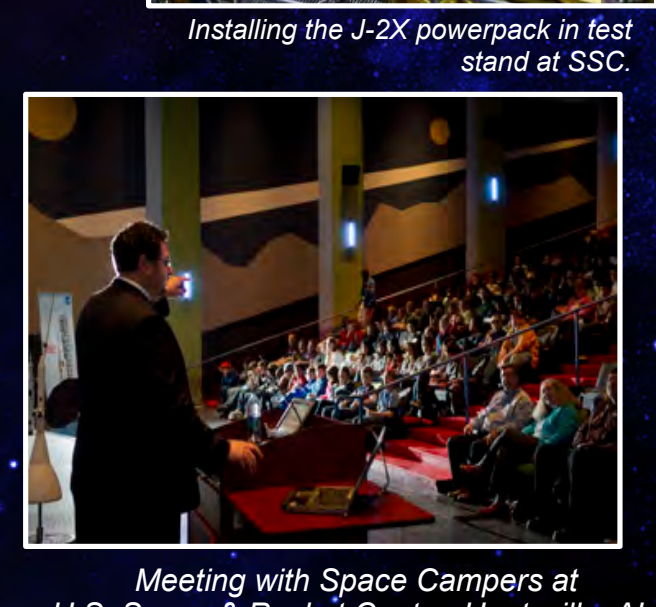
U.S. Space \& Rockèt Center, Huntsville, AL Feb 2012. 


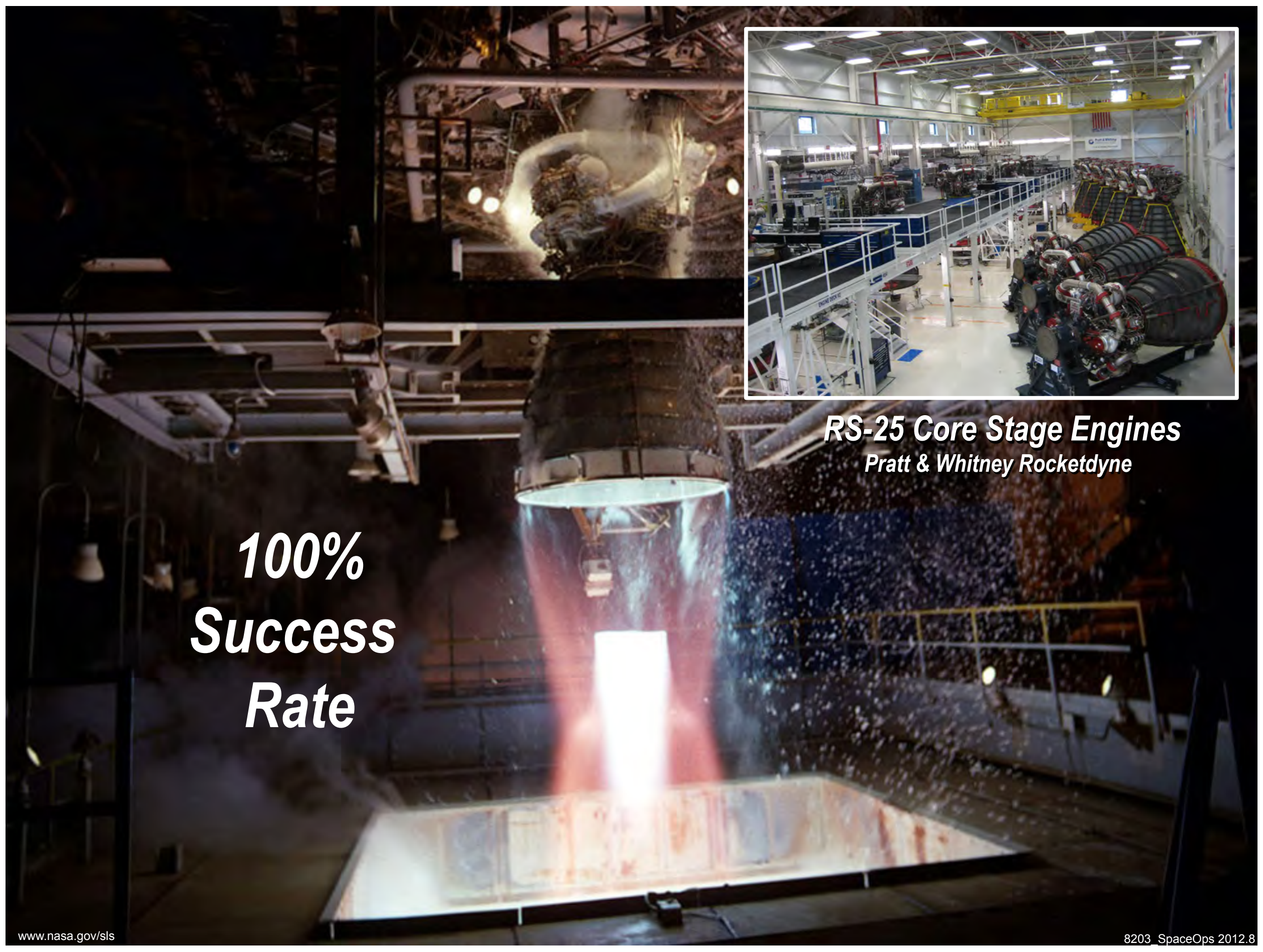




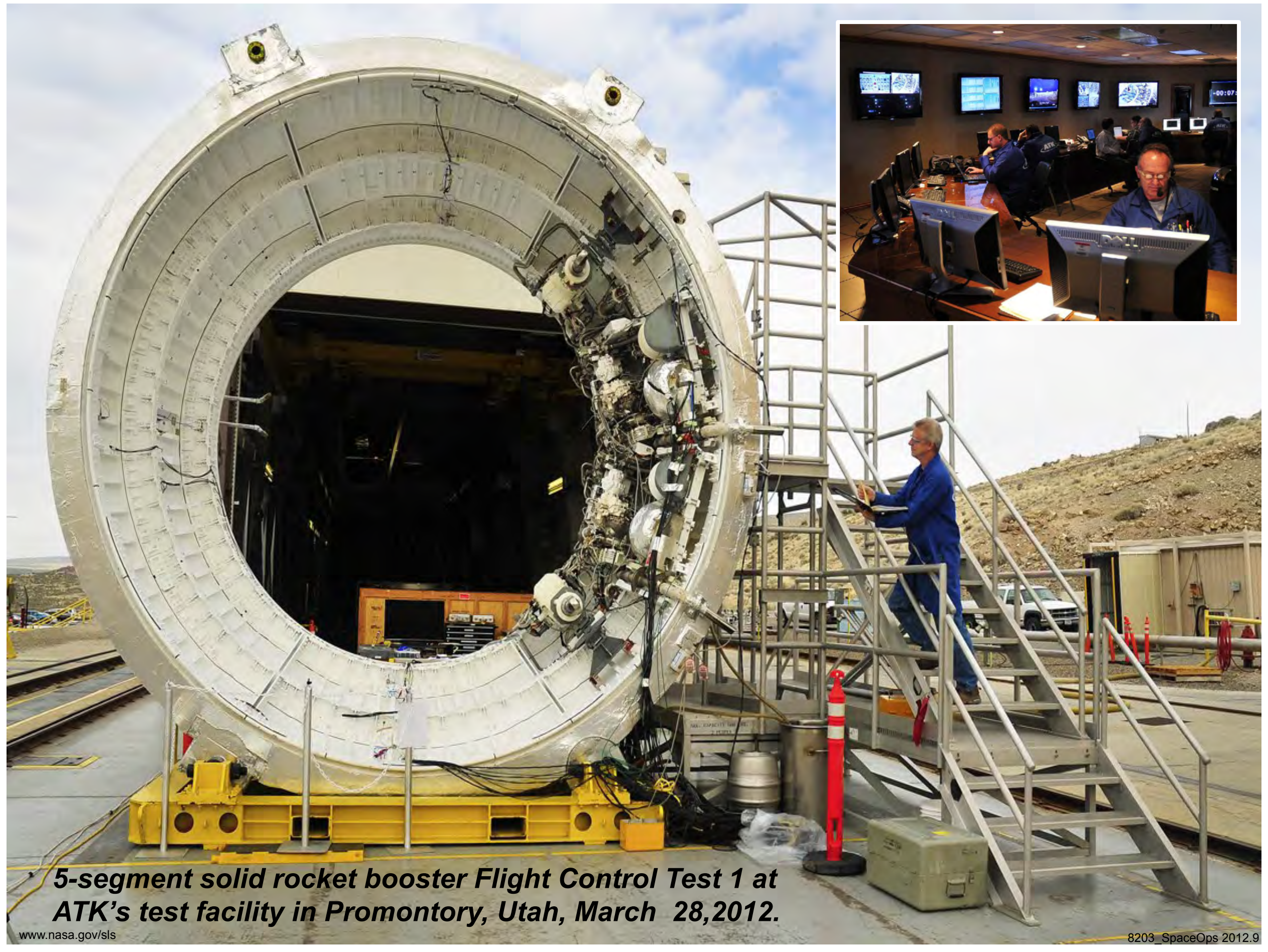




\section{J-2X Upper Stage Engine}

(Pratt \& Whitney Rocketdyne)

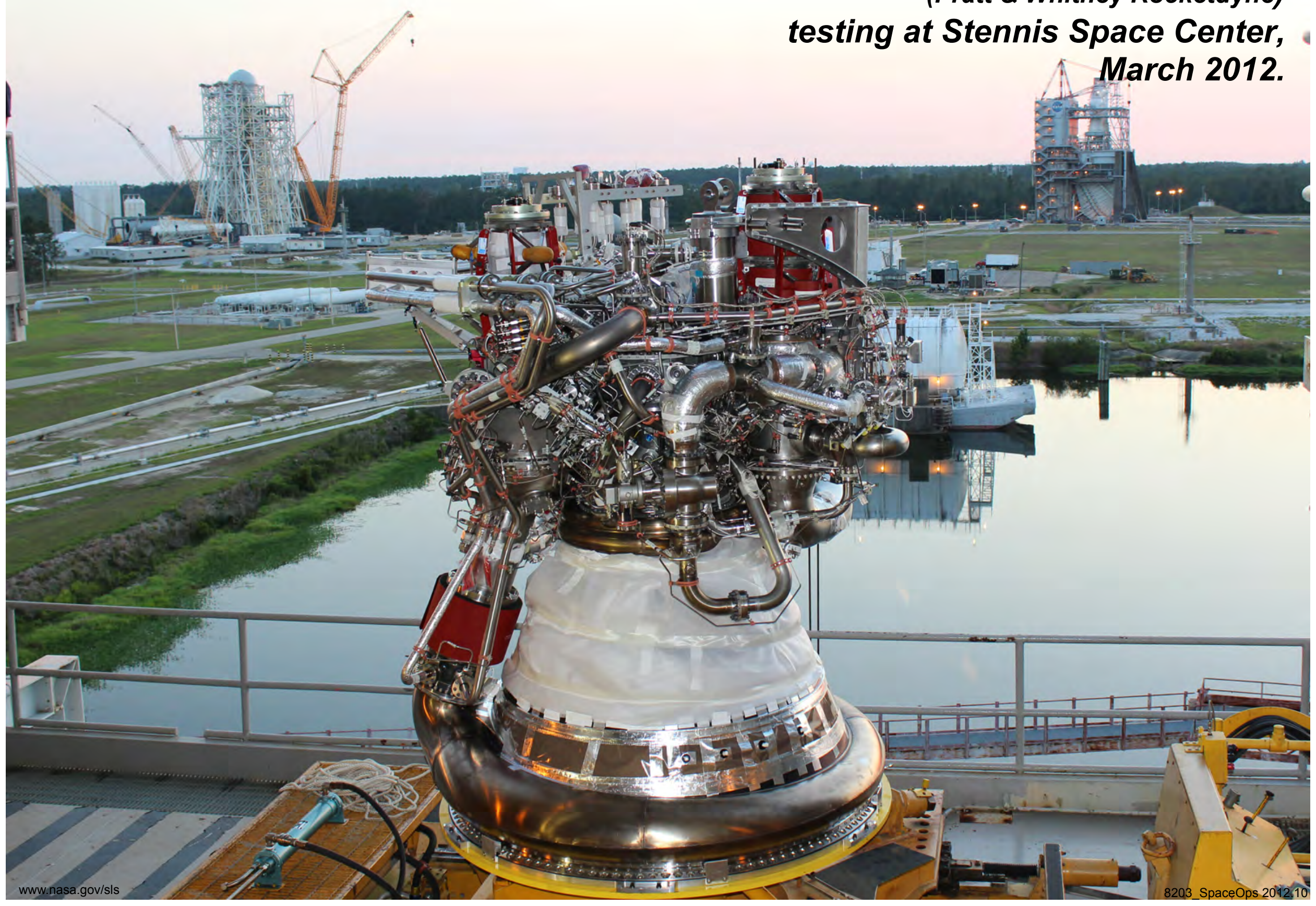




\section{Marshall Space Flight Center's Michoud Assembly Facility}

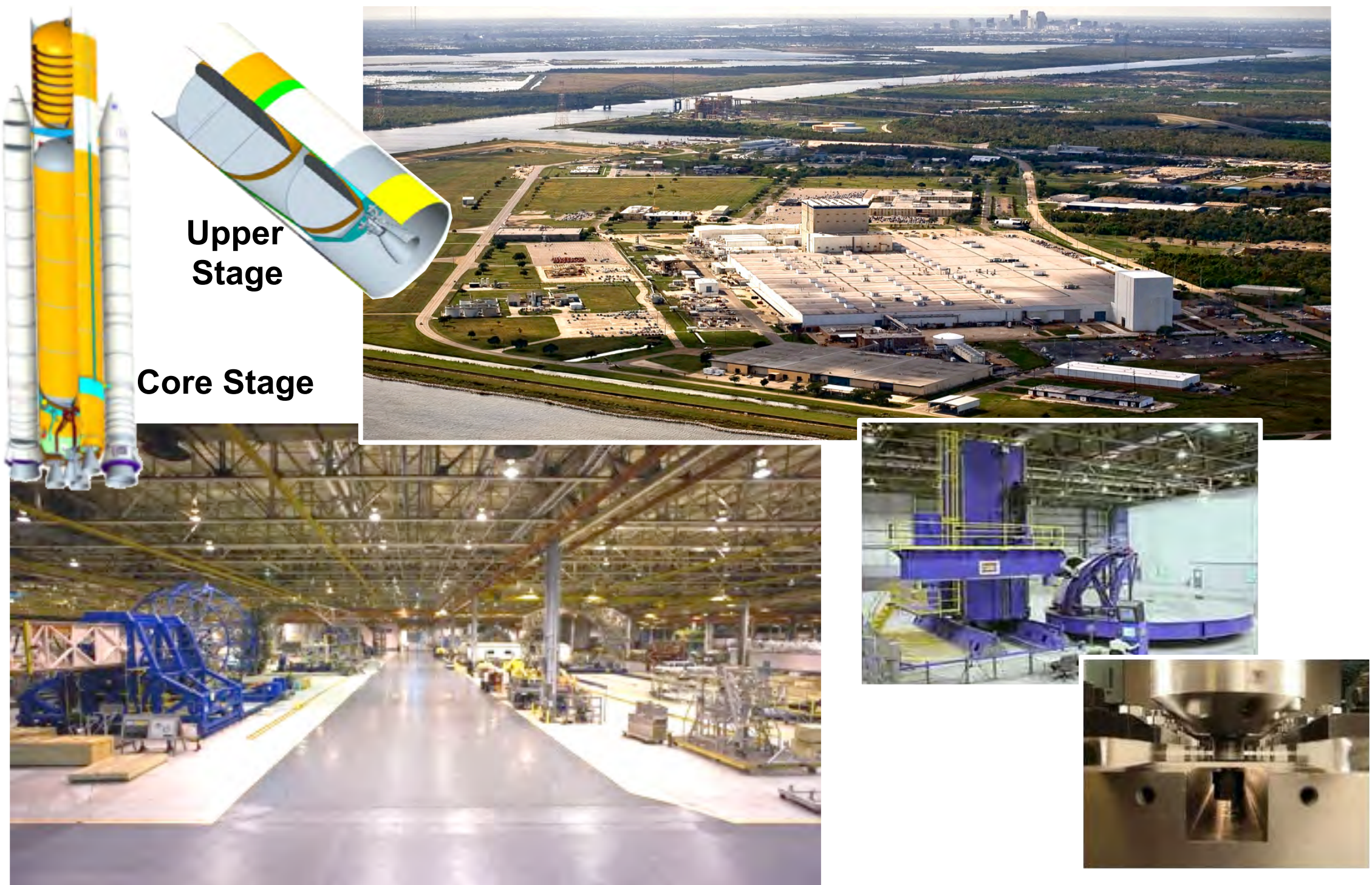

One-of-a-Kind Infrastructure Asset for Large-Structures Manufacturing 


\section{Exploration Flight Test-1 Orion MPCV Stage Adapter}

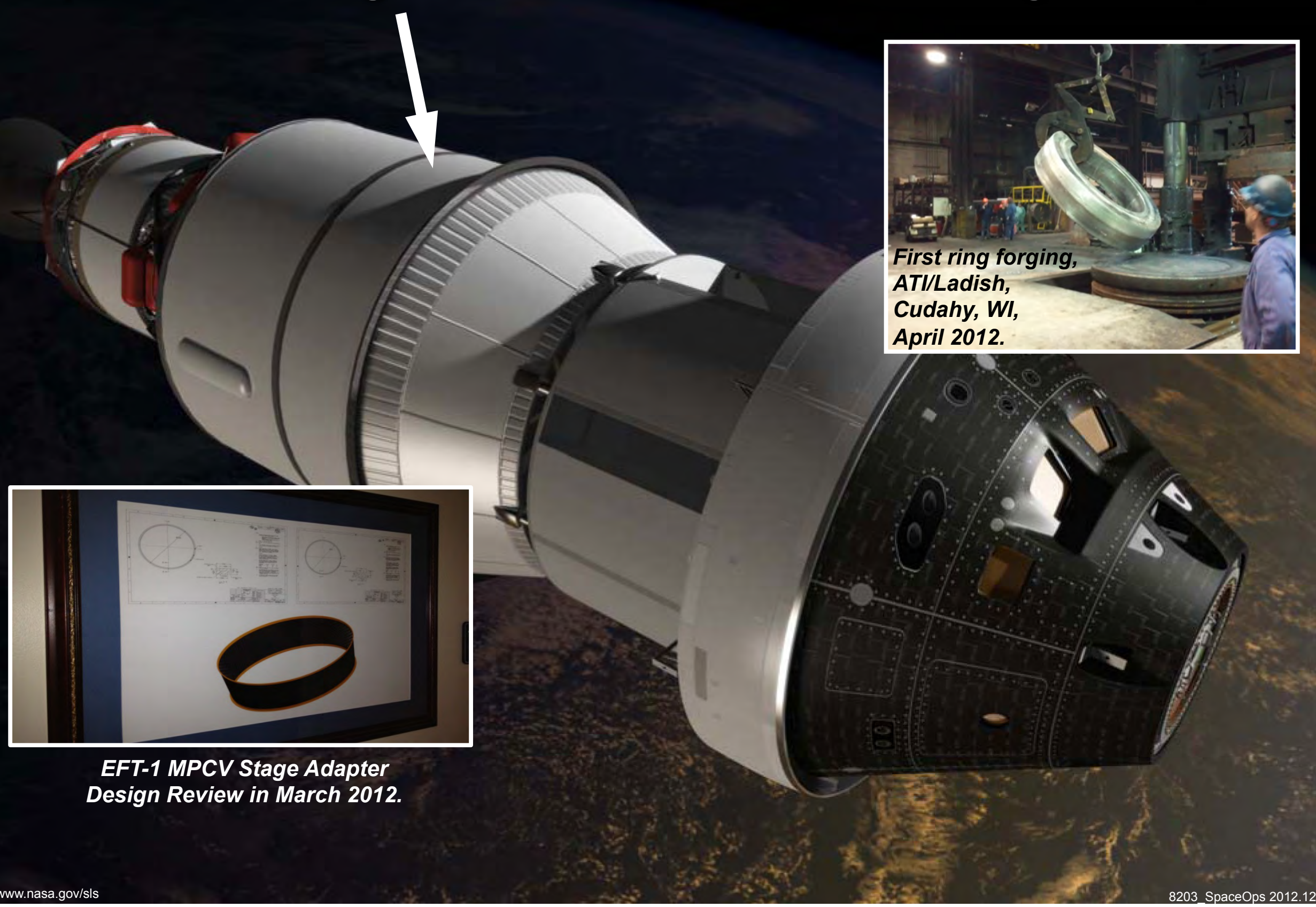




\section{SLS Affordability Begins with Accountability}

Evolvable Development Approach

Robust Designs and Margins

Risk-Informed Government Insight/Oversight Model

Right-Sized Documentation and Standards

Lean, Integrated Teams with Accelerated Decision Making
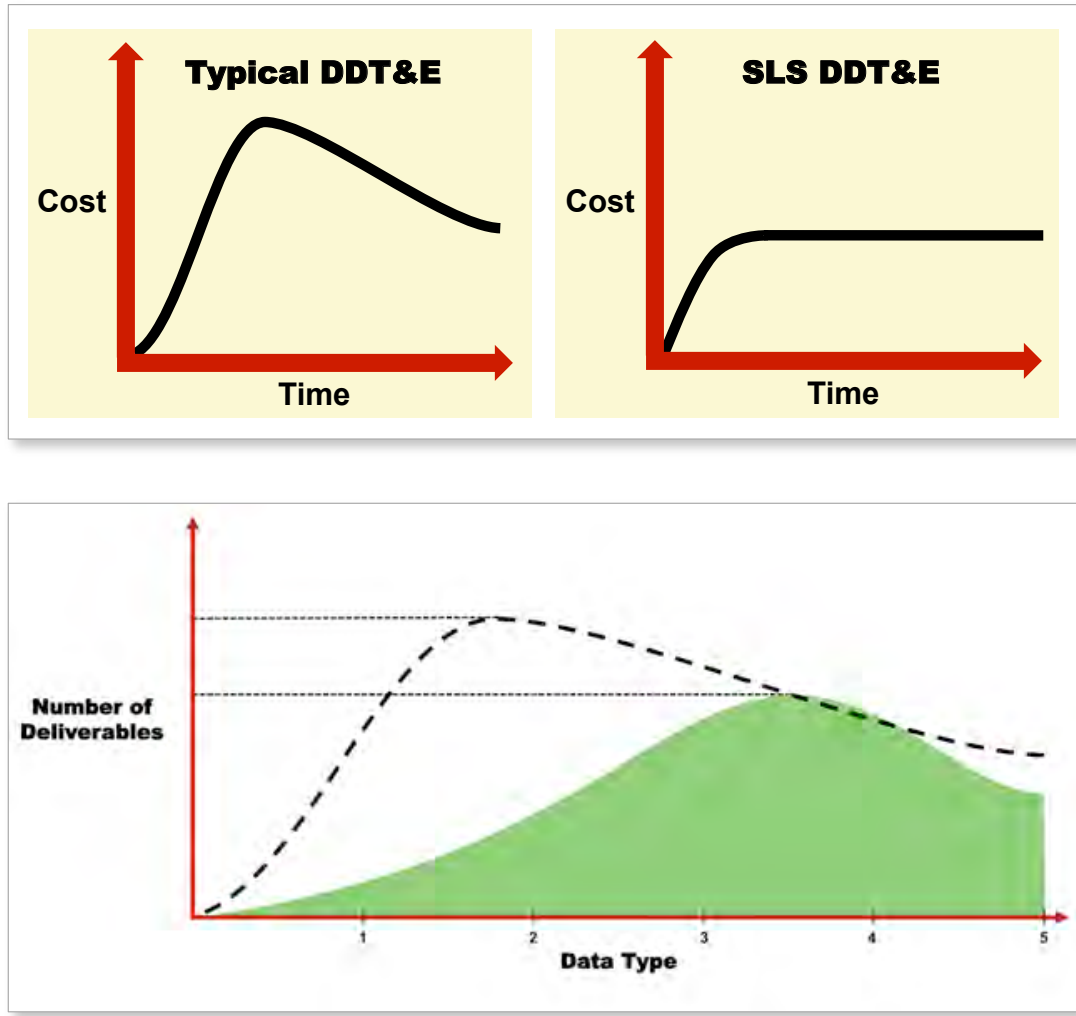

Focuses on the Data Content and Access to the Data

Affordability: The ability to develop and operate the SLS within the National means, to sustain funding for the Program. 


\section{SLS Commonalities}

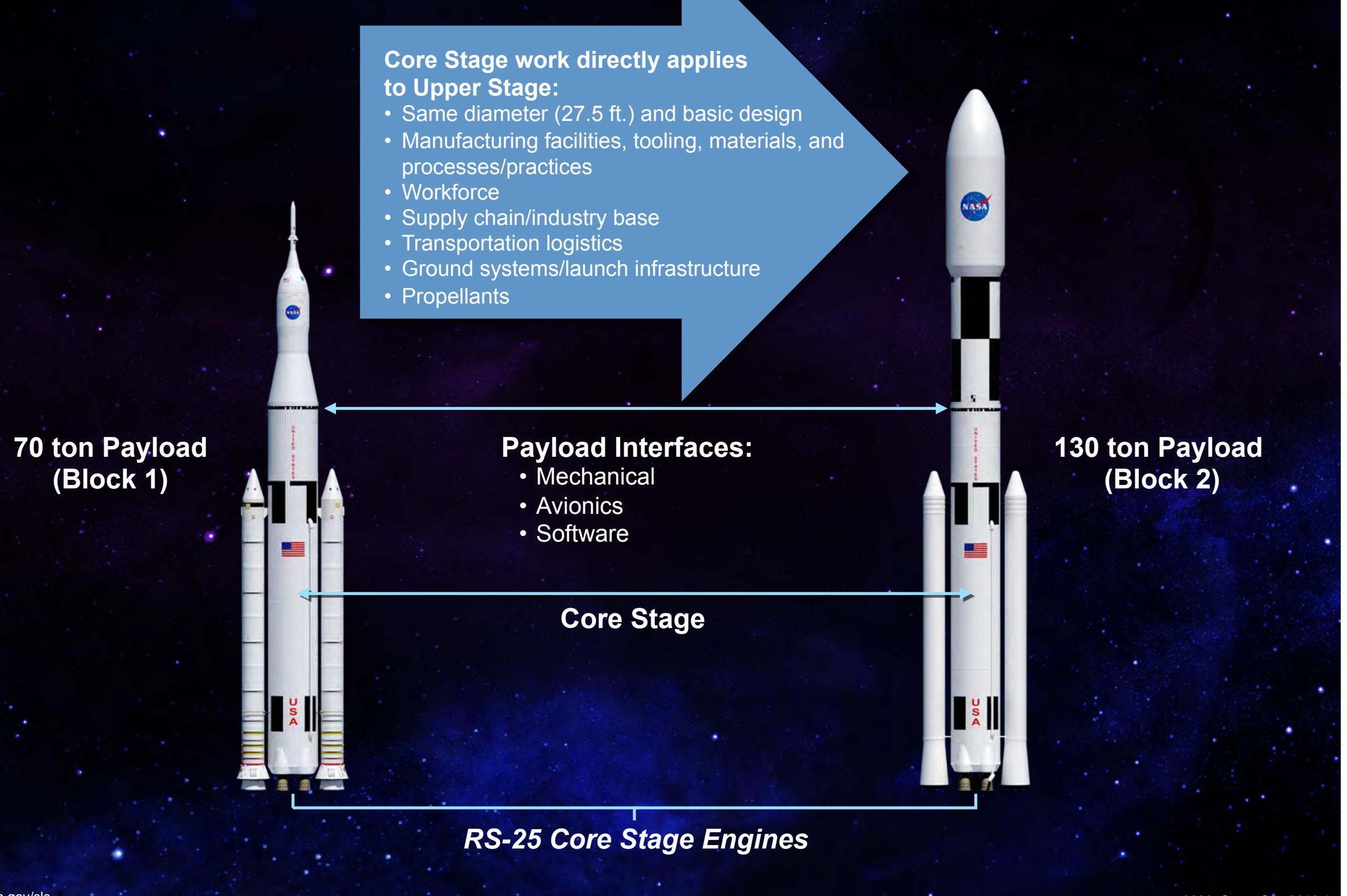




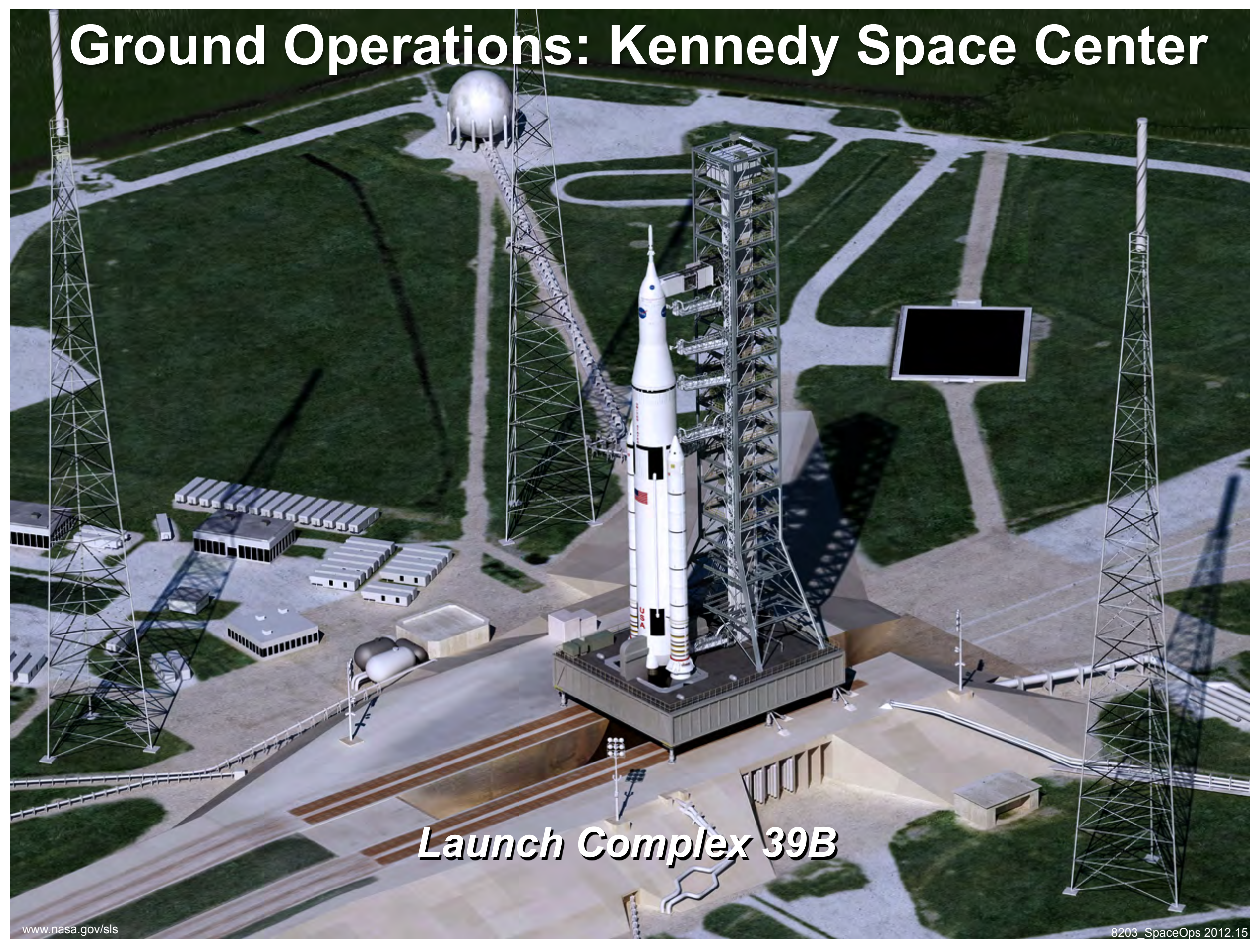




\section{A National Asset for Stakeholders and Partners}

Incremental steps to steadily build, test, refine, and qualify capabilities that lead to affordable flight elements and a deep space capability.

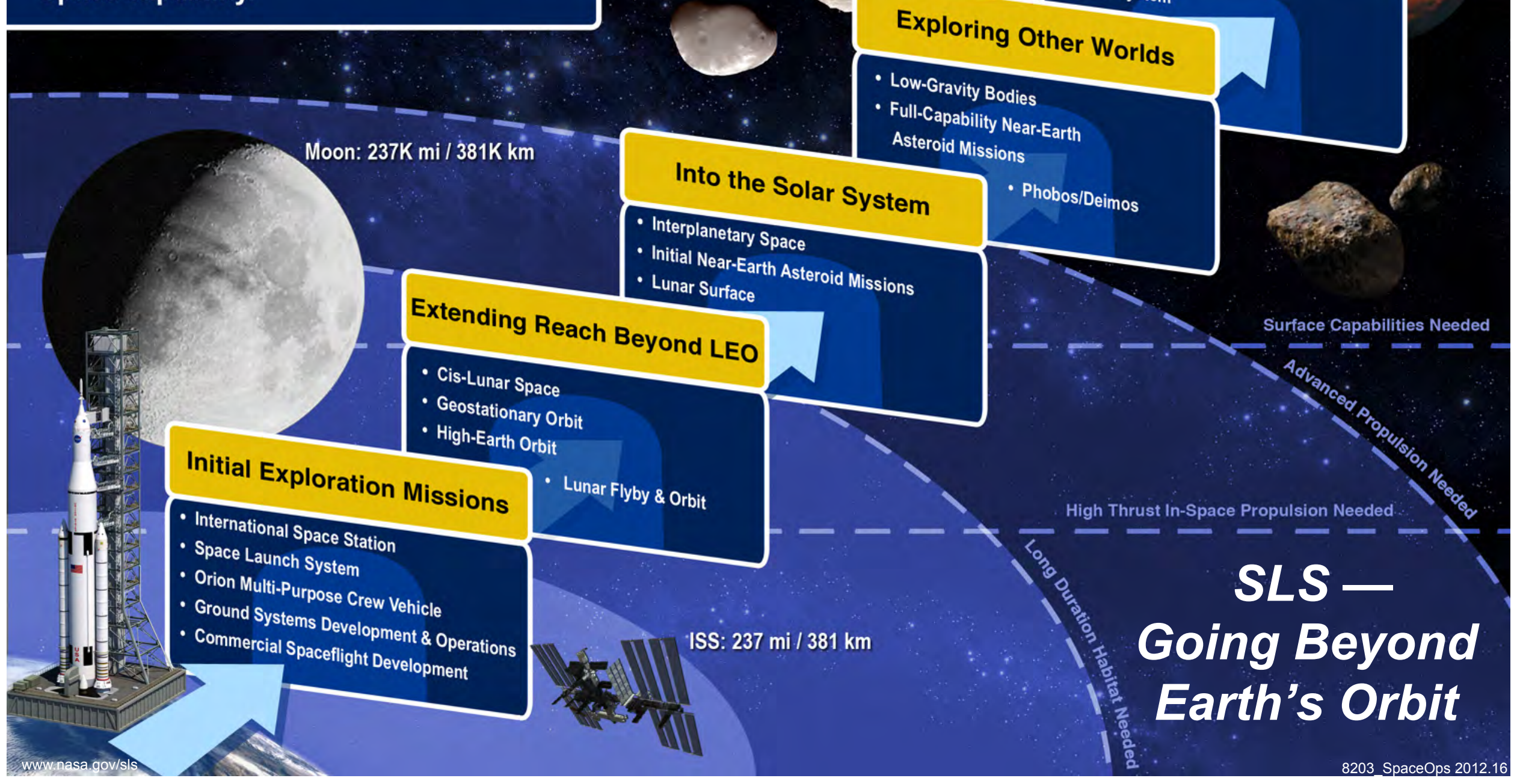




\section{NASA's Space Launch System}

- Vital to NASA's exploration strategy and the U.S. space agenda

$\checkmark$ Key tenets: safety, affordability, and sustainability

- System Requirements Review/System Definition Review and Design Analysis Cycle 2 in progress

$\checkmark$ Partnerships with NASA Exploration Systems Development (Headquarters), Orion and Ground Operations Programs, and Centers.

- Prime contractors on board, engaging the

Launching in 2017

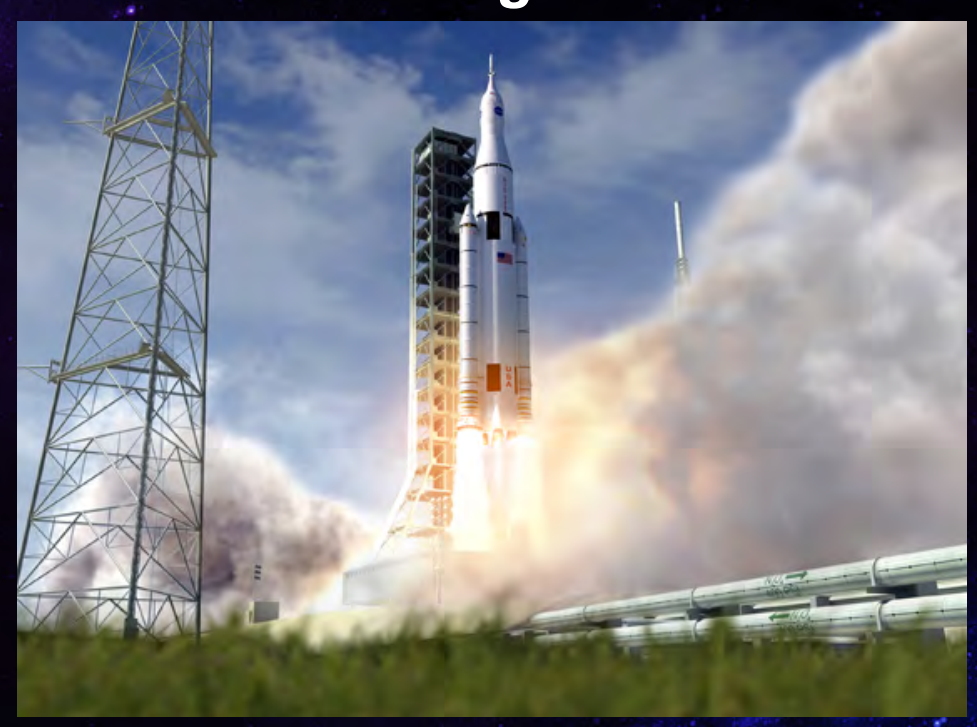

FOR MORE INFO: Www.nasa.gov/sls aerospace workforce and specialized infrastructure

$\checkmark$ Competitive opportunities for innovations that affordably upgrade performance 